\title{
Cold Spraying - a materials perspective
}

\author{
H. Assadi*, H. Kreye, F. Gärtner, T. Klassen \\ Helmut Schmidt University, Institute of Materials Engineering, Hamburg, Germany
}

\begin{abstract}
Cold spraying is a solid-state powder deposition process with several unique characteristics, allowing production of coatings or bulk components from a wide range of materials. The process has attracted much attention from academia and industry over the past two decades. The technical interest in cold spraying is twofold: first as a coating process for applications in surface technology, and second as a solid-state additive manufacturing process, offering an alternative to selective laser melting or electron beam melting methods. Moreover, cold spraying can be used to study materials behaviour under extremely high strain rates, high pressures and high cooling rates. The cold spraying process is thus considered to be relevant for various industrial applications, as well as for fundamental studies in materials science. This article aims to provide an overview of the cold spray process, the current understanding of the deposition mechanisms, and the related models and experiments, from a materials science perspective.
\end{abstract}

Keywords: Cold spraying; Coating; Additive manufacturing; Deposition mechanism; Deformation.

\footnotetext{
* Current affiliation: Brunel University London, Brunel Centre for Advanced Solidification Technology (BCAST), Uxbridge, Middlesex, United Kingdom; e-mail: hamid.assadi@brunel.ac.uk
} 


\section{Abbreviations and symbols}

\begin{tabular}{ll}
\hline Abbreviation & Meaning \\
\hline AD & Aerosol deposition \\
AM & Additive manufacturing \\
ASI & Adiabatic shear instability \\
BMG & Bulk metallic glass \\
CNT & Carbon nanotube \\
CS & Cold spraying \\
DE & Deposition efficiency \\
E-FEM & Eulerian finite element method \\
FEM & Finite element method \\
FFT & Fast Fourier transform \\
FIB & Focused ion beam \\
GND & Geometrically necessary dislocation \\
HA & Hydroxyapatite \\
L-FEM & Lagrangian finite element method \\
MD & Molecular dynamics \\
MPA & Metal powder application \\
MPW & Magnetic pulse welding \\
SEM & Scanning electron microscopy \\
\hline
\end{tabular}




\begin{tabular}{|c|c|c|}
\hline Symbol & Quantity & Units \\
\hline$a, b$ & Fitting constants in critical velocity formula & $1^{*}$ \\
\hline$A, B$ & Johnson-Cook parameters & $\mathrm{Pa}$ \\
\hline$C$ & Johnson-Cook parameter & 1 \\
\hline$c_{p}$ & Heat capacity of particle & $\mathrm{J} \mathrm{kg}^{-1} \mathrm{~K}^{-1}$ \\
\hline$d$ & Nozzle diameter & $\mathrm{m}$ \\
\hline$d_{\mathrm{p}}$ & Particle diameter & $\mathrm{m}$ \\
\hline$E$ & Total energy per unit mass of particle & $\mathrm{J} \mathrm{kg}^{-1}$ \\
\hline$E_{k}$ & Kinetic energy per unit mass of particle & $\mathrm{J} \mathrm{kg}^{-1}$ \\
\hline$E_{k}^{0}$ & Reference kinetic energy & $\mathrm{J} \mathrm{kg}^{-1}$ \\
\hline $\bar{E}_{k}$ & Normalised kinetic energy & 1 \\
\hline$E_{t h}$ & Thermal energy per unit mass of particle & $\mathrm{J} \mathrm{kg}^{-1}$ \\
\hline$E_{t h}^{0}$ & Reference thermal energy & $\mathrm{J} \mathrm{kg}^{-1}$ \\
\hline $\bar{E}_{t h}$ & Normalised thermal energy & 1 \\
\hline$f$ & Powder feed rate & $\mathrm{kg} \mathrm{s}^{-1}$ \\
\hline$F^{*}$ & Force to compress particle to height of $d_{\mathrm{p}} / 2$ & $\mathrm{~N}$ \\
\hline$l$ & Nozzle length (supersonic part) & $\mathrm{m}$ \\
\hline$l_{\text {pre }}$ & Prechamber length & $\mathrm{m}$ \\
\hline$m, n$ & Johnson-Cook parameters & 1 \\
\hline$p_{\text {gas }}$ & Process gas stagnation pressure & $\mathrm{Pa}$ \\
\hline$r$ & Nozzle expansion ratio & 1 \\
\hline$s$ & Standoff distance & $\mathrm{m}$ \\
\hline$t$ & Time & $\mathrm{s}$ \\
\hline$T$ & Temperature & $\mathrm{K}$ \\
\hline$T_{\mathrm{g}}$ & Glass transition temperature & $\mathrm{K}$ \\
\hline$T_{\mathrm{gas}}$ & Process gas stagnation temperature & $\mathrm{K}$ \\
\hline
\end{tabular}




\begin{tabular}{|c|c|c|}
\hline$T_{\mathrm{m}}$ & Melting temperature & $\mathrm{K}$ \\
\hline$T_{\mathrm{p}}$ & Particle temperature & $\mathrm{K}$ \\
\hline$T_{\text {ref }}$ & Reference temperature & $\mathrm{K}$ \\
\hline$T_{\text {sub }}$ & Substrate temperature & $\mathrm{K}$ \\
\hline$T_{\mathrm{x}}$ & Crystallisation temperature & $\mathrm{K}$ \\
\hline$v_{\mathrm{c}}$ & Velocity of contact point in explosive welding & $\mathrm{m} \mathrm{s}^{-1}$ \\
\hline$v_{\mathrm{cr}}$ & Critical particle impact velocity for bonding & $\mathrm{m} \mathrm{s}^{-1}$ \\
\hline$v_{\text {gun }}$ & Traverse speed of gun & $\mathrm{m} \mathrm{s}^{-1}$ \\
\hline$v_{\mathrm{p}}$ & Particle impact velocity & $\mathrm{m} \mathrm{s}^{-1}$ \\
\hline$x$ & Characteristic system dimension & $\mathrm{m}$ \\
\hline$\alpha$ & Thermal diffusivity & $\mathrm{m}^{2} \mathrm{~s}^{-1}$ \\
\hline$\beta$ & Adiabaticity parameter $\left(x^{2} / \alpha / t\right)$ & 1 \\
\hline$\varepsilon$ & Plastic strain & 1 \\
\hline$\dot{\varepsilon}$ & Plastic strain rate & $\mathrm{s}^{-1}$ \\
\hline$\dot{\varepsilon}^{*}$ & Normalised plastic strain rate & 1 \\
\hline$\gamma_{\text {cr }}$ & Critical shear strain at the start of localisation & 1 \\
\hline$\gamma_{\max \text { stress }}$ & Strain at max stress in adiabatic deformation & 1 \\
\hline$\eta$ & Normalised particle impact velocity $\left(v_{\mathrm{p}} / v_{\mathrm{cr}}\right)$ & 1 \\
\hline$\eta_{E}$ & Sum of normalised energy terms $\left(\bar{E}_{k}+\bar{E}_{t h}\right)$ & 1 \\
\hline$\theta$ & Normalised temperature & 1 \\
\hline$\rho$ & Density of particle & $\mathrm{kg} \mathrm{m}^{-3}$ \\
\hline$\sigma$ & Flow stress & $\mathrm{Pa}$ \\
\hline$\sigma_{\mathrm{UTS}}$ & Ultimate tensile strength of particle & $\mathrm{Pa}$ \\
\hline$\omega$ & Spraying angle & 1 \\
\hline
\end{tabular}

* 1 indicates dimensionless quantity. 


\section{Introduction}

Cold spraying (CS) is a solid-state material deposition technique, where micron-sized particles of a powder bond to a substrate as a result of high-velocity impact and the associated severe plastic deformation. Acceleration of particles to high velocities is obtained via expansion of a pressurised and (ironically) 'hot' gas through a diverging-converging nozzle. Despite heating the process gas - which is to provide higher acceleration of the gas and also to facilitate particle deformation through thermal softening - the feedstock remains in the solid state throughout the entire process; hence the name 'cold' spraying. This is to underline the contrast to conventional thermal spraying where particles are completely or partially molten upon impact onto the substrate. Alternative terminology includes cold gas spray, micro cold spray, cold gas dynamic spray, kinetic spray, supersonic particle deposition and metal powder application (MPA), all of which refer to the same principle of solid-state powder deposition as described above. CS is used for coating and repair. It is also used for additive manufacturing (AM) at relatively high deposition rates as compared to the methods based on selective laser or electron beam melting. The main advantage of CS is that it alleviates the problems associated with high temperature processing of materials, such as oxidation and unfavourable structural changes. It is possibly the only continuous method to produce bulk components of metastable materials that are available only in the powder form, e.g. as obtained from mechanical attrition or gas atomisation.

The invention of modern CS took place, somewhat serendipitously, in Russia about three decades ago. The initial patents are already more than 20 years old [1-3] but there have been a growing number of related patents since the invention of CS [4]. Early academic papers (in English) by the inventors and co-workers appeared about the same time [5-9]. These were shortly followed by others, e.g. Dykhuizen and Smith [10] Gilmore et al. [11] van Steenkiste et al. [12] Kreye and Stoltenhoff [13] and Xiong et al. [14]. The interest in CS has been increasing at a relatively fast rate in the past two decades, as reflected by the number of publications per year, Fig. 1. Scholarly publications on CS include several books and review articles, covering various aspects of the process and its applications [15-23]. The topic is broad and spans over various fields of research, from fluid dynamics to solid mechanics. Even from materials perspective, there are various aspects regarding material properties and relevant physical phenomena that deserve separate reviews. 


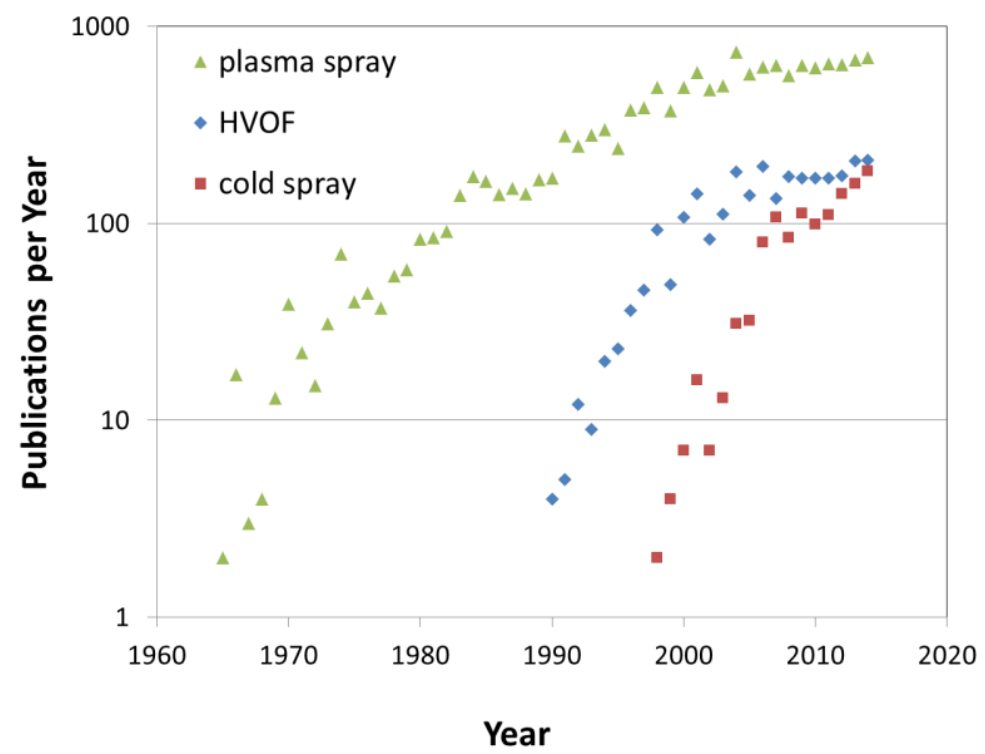

Figure 1. Trend of interest in cold spray research as measured by the number of publications per year, as compared to that in plasma spraying and high-velocity oxy-fuel spraying (data extracted from scopus.com).

The aim of the present paper is to provide an overview of CS from a materials perspective, particularly for a broader audience in materials research, e.g. with interest in dynamic phenomena, plasticity and phase transformations. In terms of application and properties, CS is perhaps best to be compared to thermal spraying processes, as in [24, 25]. In view of relevant physical phenomena, however, CS is most closely related to explosive powder shock compaction, magnetic pulse welding (MPW) [26] and explosive welding. Likewise, some of the conventional thermal spraying processes, such as arc or plasma spraying where there is extensive melting and resolidification, may be best compared to fusion welding from the viewpoint of solidification science. This paper covers principles of CS, put into perspective by considering common features of material deposition methods using high-velocity impact. A brief review of the key CS parameters and typical material systems are also presented.

\section{Principle and setup}

The main technical objective in CS is to ensure that the particles of the feedstock powder impinge the substrate at or beyond a critical velocity. This is achieved by means of a pressurised and preheated process gas - typically nitrogen, in some cases helium - that 
expands through a (converging/diverging) de Laval nozzle, reaching supersonic velocities $[13,27]$. Figure 2 shows an overview of a high-pressure CS system. In this system, a fluidised powder feedstock is fed to the process gas upstream, i.e. at high pressure before entering the nozzle. The particles of the powder are thus accelerated by the process gas, reaching high velocities of up to $1200 \mathrm{~m} / \mathrm{s}$ or more. The particle temperature upon impact can be $1000 \mathrm{~K}$ or more, depending on the process conditions. Powder preheating is attained through a powder heater installed between the powder feeder and the gun [28], or more conventionally, through an elongated prechamber just before the nozzle.
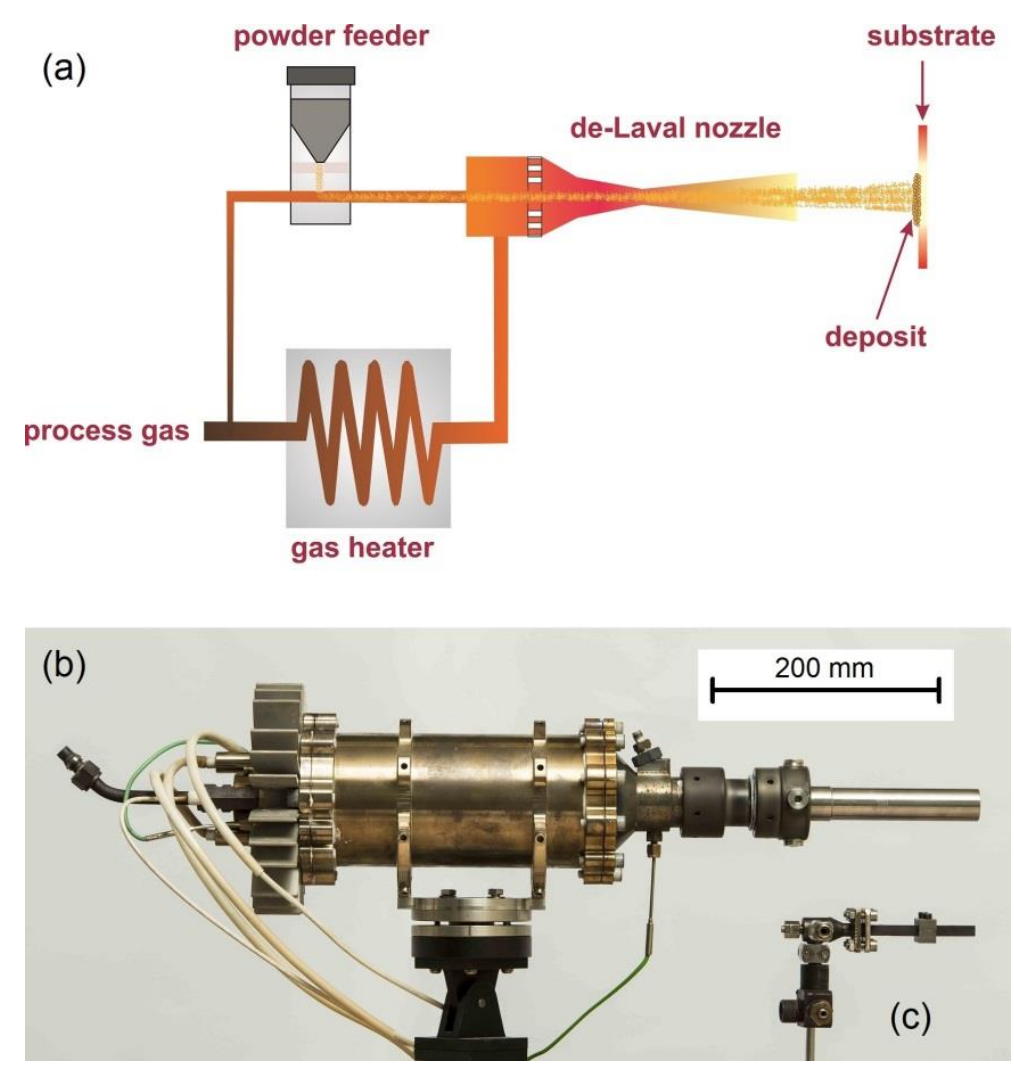

Figure 2. An overview of a high-pressure cold spray system: (a) schematics of the main components of the original system, (b) a commercialised cold spray gun/nozzle, designed at Helmut Schmidt University, and (c) an original gun/nozzle developed by Anatolii Papyrin. The guns labelled (b) and (c) are in the same photo and have equal distances from the camera. The focus of the present paper is on high-pressure CS, where the gas pressure is typically above $1 \mathrm{MPa}$, the particles are micron-sized, and the operation is conducted at open air or under near-atmospheric pressure. Variations and modifications of CS are not covered in this review. Some of these variations are briefly mentioned below. 
Low-pressure cold spray system and high-pressure systems were developed in parallel. There is substantial difference between the two processes in terms of the size and the cost of the available commercial equipment, as well as the achievable impact velocities and temperatures. The scope of application of low-pressure systems is hence limited. An example of comparison between high-pressure and low-pressure CS is given by Koivuluoto et al. [29].

\section{Vacuum cold spray}

Also known as aerosol deposition (AD) [30], vacuum cold spray is a downscaled variation of $\mathrm{CS}$, which uses submicron powders and works under partial vacuum. It is commonly used to apply ceramic coatings. The process is attracting a growing interest, particularly for electronic device applications. A recent review on AD is provided by Hanft et al. [31].

\section{Laser-assisted cold spray}

In this technique CS is used in parallel with laser heating [32, 33]. The laser is coupled to cold spray either as a means of surface preparation [34], or to enhance bonding by providing additional heat input mainly in low-pressure cold spray [35].

\section{Electrostatic-force-assisted cold spray}

The use of an electrostatic field in parallel with CS has been considered conceptually in a few theoretical studies $[36,37]$. The idea has been to accelerate the particle further by means of electrostatic field and so to enhance particle impact velocity. This concept has apparently not yet been implemented.

\section{Deposition mechanism}

Material deposition by CS results from consecutive impacts of micron-sized solid particles on a substrate. The particle impact is associated with viscoplastic deformation of the interacting bodies, leading to (1) sequential compaction of the feedstock powder into a deposit, and (2) 
metallurgical bonding over a significant fraction of the particle-particle interfaces. Both of these processes are central to obtaining a dense and strong deposit; incomplete compaction results in high porosity, whereas poor bonding results in low strength of the deposit. On the other hand, both compaction and bonding processes take place via particle impact and the resulting severe deformation. Therefore, understanding the deposition mechanism is CS requires an understanding of particle deformation.

\subsection{Modelling of particle impact and deformation}

Particles of cold spray powders are typically $10-50 \mu \mathrm{m}$ in diameter, and the process of particle impact - from the time of initial contact to total dissipation of kinetic energy - takes about $100 \mathrm{~ns}$. At such small time and length scales, experimental monitoring with sufficient resolution of particle impact and the related phenomena is conceivably difficult, if at all possible. As an alternative, numerical simulation of particle impact is used to provide an insight to these phenomena. The simulations are normally based on quantitative models of well-defined underlying physics, which are conceived to play a role in material deposition by CS. A major fraction of the modelling and simulation work in this area has focused on an idealised case of perpendicular impact of a single spherical particle on a flat substrate of the same material.

\subsubsection{Underlying physics and material models}

There are several physical phenomena that play a role in the process of deposition in CS of deformable materials. The most important of these is viscoplastic deformation, which occurs under dynamic shear loading. In comparison, the elastic deformation of material plays a lesser role, and is therefore not central to modelling of particle impact. Modelling of viscoplastic deformation is usually pursued together with modelling of heat conduction. The thermomechanical behaviour of material under high strain rate is often described through constitutive equations that link the flow stress $(\sigma)$ to strain $(\varepsilon)$, strain rate $(\dot{\varepsilon})$ and temperature (T). An example of such equations, among many, is given by Johnson and Cook [38] as follows

$$
\sigma=\left(A+B \varepsilon^{n}\right)\left(1+C \ln \dot{\varepsilon}^{*}\right)\left(1-\theta^{m}\right)
$$


where $\dot{\varepsilon}^{*}$ is the equivalent plastic strain rate normalised with respect to a reference strain rate, and $\theta=\left(T-T_{\text {ref }}\right) /\left(T_{\mathrm{m}}-T_{\text {ref }}\right)$ is the normalised temperature in which $T_{\text {ref }}$ is a reference temperature (normally taken as room temperature), and $T_{\mathrm{m}}$ is the melting temperature. A number of other material models can be used for this purpose, e.g. as considered in [39]. While some models appear to be more appropriate than others, selection of 'the best' material model remains a challenge. A main reason is that material data hardly exist for the range of strain rates in CS - which can be as high as $10^{9} \mathrm{~s}^{-1}$ [40]. Even for the low-strain-rate regime, there are limited data available on the plastic constitutive properties of materials in the form of micron-sized particles. Such data have been evaluated for a few powder materials, such as copper and MCrAlY using a single particle compression method [41] as described in section 5. Moreover, accurate simulation of deformation during particle impact requires further refinements, in addition to that of plastic constitutive properties, which are yet to be implemented. These include the possible influence of strain gradients [42] on the deformation pattern during particle impact. Under strain gradients, additional hardening may occur due to the generation of geometrically necessary dislocations (GNDs) [43]. There can also be additional softening due to microstructural changes, namely dynamic recrystallization [44], which has not been widely considered in the modelling of particle impact. It should be noted that the thermal softening as considered in constitutive equations, as in Eq. (1), relates to thermally-activated dislocation movement, and not to microstructural changes.

The work required for viscoplastic deformation is provided by the kinetic energy of the impacting particle, a major fraction of which is converted into heat during impact. The rest of the kinetic energy, considered roughly to be less than $10 \%$, is stored within the material as elastic energy associated with defects or residual stress. The generated heat can dissipate through conduction, though this is sometimes neglected, i.e. deformation is assumed to be adiabatic. The assumption of adiabaticity is valid only when the system dimension $(x)$ is significantly greater than the thermal diffusion distance $(\sim \sqrt{\alpha t})$. This is when:

$$
\frac{x^{2}}{\alpha t}=\beta>>1
$$

in which $x$ is a characteristic system dimension, $\alpha$ is the thermal diffusivity, $t$ is the process time, and $\beta$ is a dimensionless parameter representing the degree of adiabaticity. Considering 
that $x$ scales with the particle diameter, $d_{\mathrm{p}}$, and assuming that $t$ scales with the ratio of $d_{\mathrm{p}}$ to impact velocity, $v_{\mathrm{p}}$, then it can be shown that:

$$
\beta \propto d_{\mathrm{p}} v_{\mathrm{p}}
$$

This means that for the same impact velocity, larger particles deform more adiabatically, and vice versa. In fact, only very large particles satisfy this condition [45]. Therefore, heat transfer should be considered for detailed quantitative analysis of particle deformation - particularly when the role of particle size in deposition is to be considered.

The heat generation during plastic deformation, especially under high-strain rates, may lead to strain localisation and shear instability. This condition is normally manifested as shear banding and failure in bulk materials [46]. As shown in Fig. 3, during shear deformation of a bulk component thermal softening may dominate over strain and strain-rate hardening under adiabatic conditions, leading to overall strain softening. During strain softening, the material becomes inherently unstable with respect to plastic deformation, so that localization and shear banding may occur at a critical strain, $\gamma_{\mathrm{cr}}$. Beyond this point, the local strain at the shear band increases sharply to high values, while the overall strain remains almost unchanged up to the point of rupture. As will be discussed later in more detail, this phenomenon is considered to be closely related to particle bonding in CS [40].

The above concepts are applicable mainly to crystalline metals and alloys, with typical work hardening and thermally-activated deformation behaviours. For other materials, different material models and alternative analytical approaches may be needed. For instance, for the case of metallic glasses there is strain softening instead of work hardening, so that the material is always susceptible to instability and shear banding. In contrast, for some intermetallic compounds instability may be difficult to achieve due to anomalous (nonmonotonic) thermal softening - e.g. increase of strength with increasing temperature up to $800{ }^{\circ} \mathrm{C}$ as in the case of $\mathrm{Ni}_{3} \mathrm{Al}$. For ceramic materials, plastic deformation is not conceivable, so that alternative concepts and entirely different and material models should be used to explain the deposition process. These additional considerations will be briefly discussed later. 


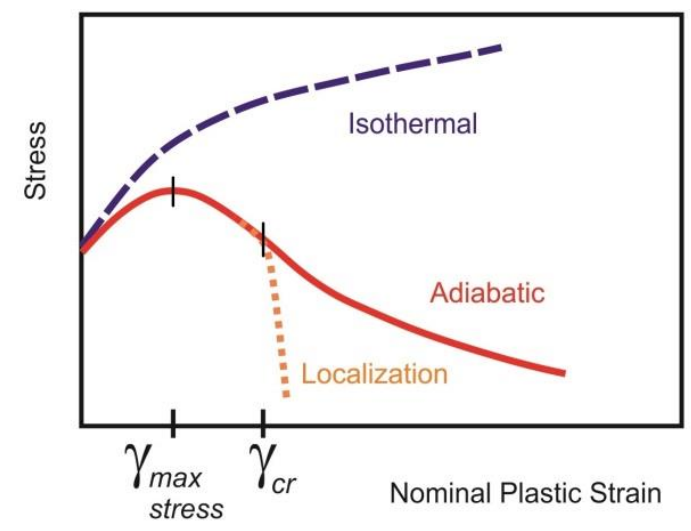

Figure 3. Schematics of stress-strain variation for a typical bulk metallic material during torsion experiment [47].

\subsubsection{Numerical simulation}

Modelling of particle impact and deformation is mostly performed using mesh-based numerical methods such as finite-element method (FEM). The main objective of numerical simulation is to work out temporal evolution of the deformation pattern and the respective field variables (stress, strain and temperature) for various combinations of materials and impact conditions - i.e. particle velocity, particle temperature and substrate temperature. The results of numerical simulations are subsequently used for the interpretation of particle bonding and coating formation. A recent review of the work on modelling of particle impact is given by Li et al. [48]. An overview of the employed numerical methods, their main outcome and possible future directions are given below.

FEM has been most widely used in simulation of particle impact and deformation in CS. Nevertheless, most work in the literature is about single particle impact and not complete build-up of a coating. A pioneering example is given by Dykhuizen et al. [49]. They considered an axisymmetric model of particle impact under adiabatic conditions, using CTH, an Eulerian-based FEM software package developed at Sandia National Laboratories [50]. Their simulations showed the development of shape and field variables, such as temperature, during impact of a copper particle on a steel substrate for different impact velocities. These simulations indicated formation of material jets at the outer rim of the contact zone, similar to that observed in explosive welding, at impact velocities higher than $400 \mathrm{~m} / \mathrm{s}$. Following this work, Assadi et al. simulated particle impact using the Lagrangian formulation in 
Abaqus/Explicit [40], with a focus on the evolution of the field variables near the interacting surfaces. Examples of the simulated deformation patterns are shown in Fig. 4.

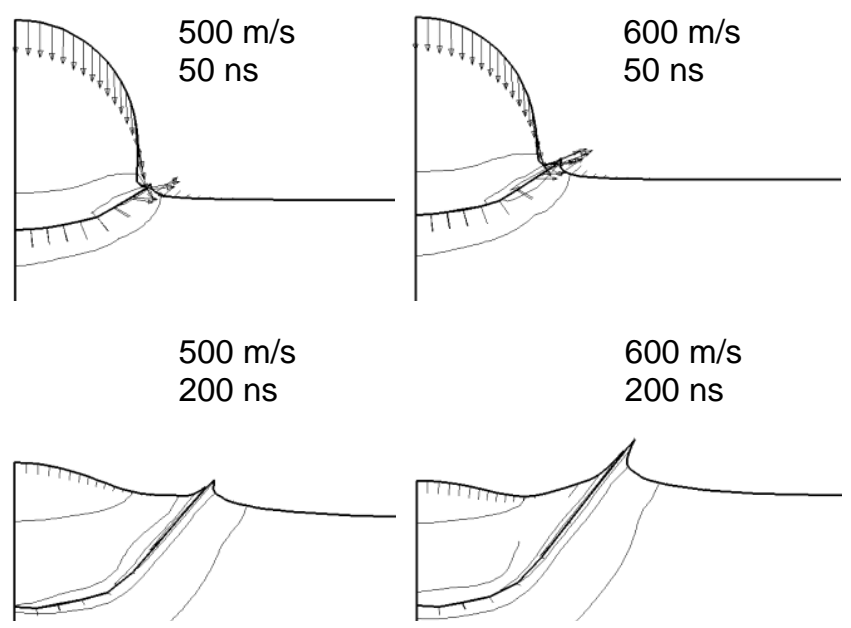

Figure 4. Lagrangian-based FEM simulation of impact of a copper particle on copper substrate, assuming adiabatic conditions [40]. The contours and the arrows correspond to strain and velocity fields, respectively.

A main outcome of these simulations was to demonstrate that adiabatic shear instability (ASI) could occur at the particle/substrate interface during particle impact. ASI was signified by sudden and prominent rise in the plastic strain at the interacting surfaces, Fig. 5.
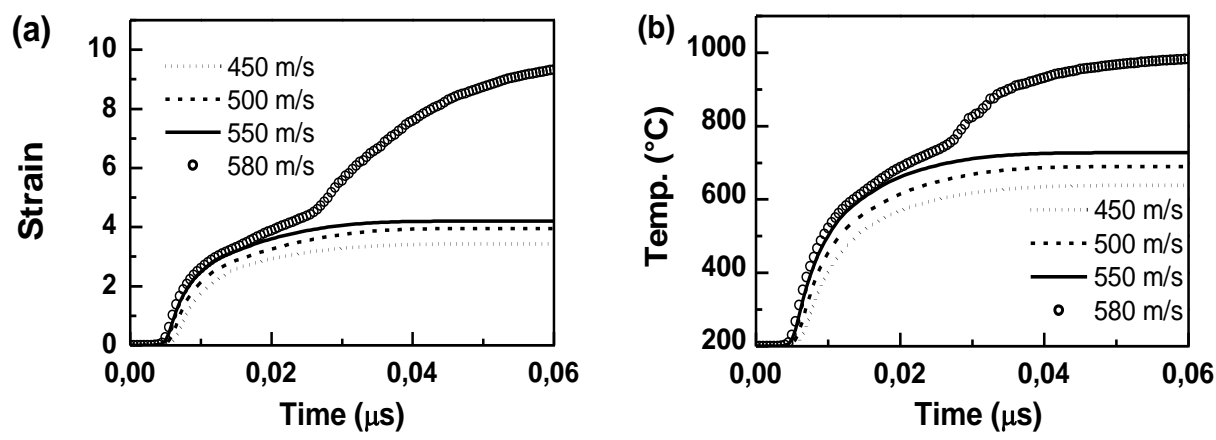

Figure 5. Calculated development of (a) maximum plastic strain and (b) maximum temperature on the surface of a copper particle impacting onto a copper substrate. Adiabatic shear instability is indicated by a sudden rise in these variables, if the impact velocity exceeds $550 \mathrm{~m} / \mathrm{s}$ by $30 \mathrm{~m} / \mathrm{s}[40]$.

A number of factors - both physical and computational - were found to influence the occurrence of ASI in the simulation of particle impact. Physical factors include density, strength, melting temperature and specific heat of the interacting materials. These factors will 
be discussed in more detail in the next section on bonding criteria. A most important computational factor is mesh size, which strongly affects ASI; the coarser the mesh, the higher the threshold impact velocity to induce shear instability. Another computational factor is whether deformation is considered to be fully adiabatic or not; ASI may occur prematurely if heat transfer is not considered.

This role of heat transfer can be used as a basis to study the effect of particle size on the occurrence of ASI during impact [45]. According to Eq. (2), deformation in larger particles is more adiabatic, so that ASI becomes more prominent with increasing particle size. As shown in Fig. 6, ASI occurs only when both particle impact velocity and particle size are beyond a certain value.

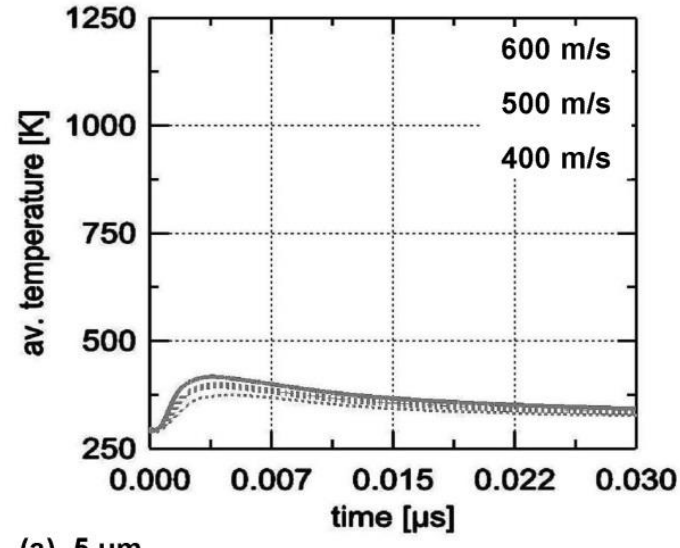

(a) $5 \mu \mathrm{m}$

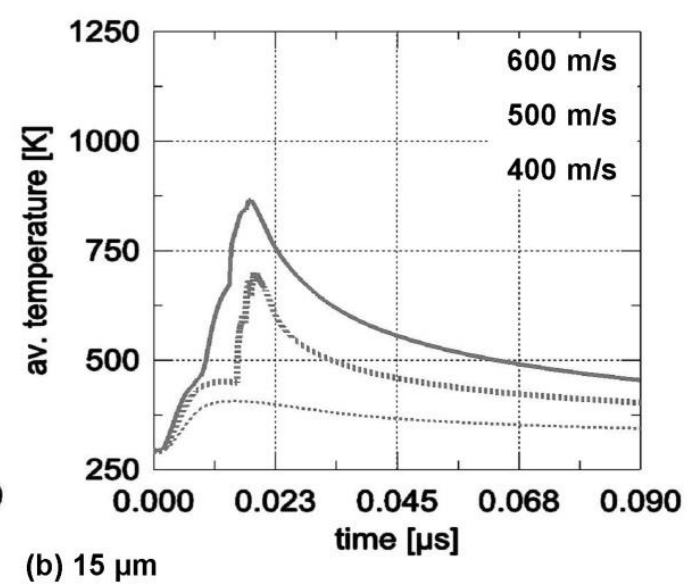

(b) $15 \mu \mathrm{m}$

Figure 6. Calculated development of maximum temperature on the surface of (a) $5 \mu \mathrm{m}$, and (b) $15 \mu \mathrm{m}$ copper particle impacting onto a copper substrate at different impact velocities.

Adiabatic shear instability occurs only in the larger particle, at or beyond $500 \mathrm{~m} / \mathrm{s}$ [45].

The prediction of ASI preceded experimental evidence, and hence may be regarded as a significant outcome of simulations. An equally important prediction concerned the location and the extent of ASI. As shown in Fig. 7, ASI occurs initially at the outer rim of the particle/substrate contact zone. With the increase of particle impact velocity, the ASI area extends from the circumference of the crater towards its centre. According to this prediction, the ASI never reaches the centre regardless of the particle impact velocity. 
(a)

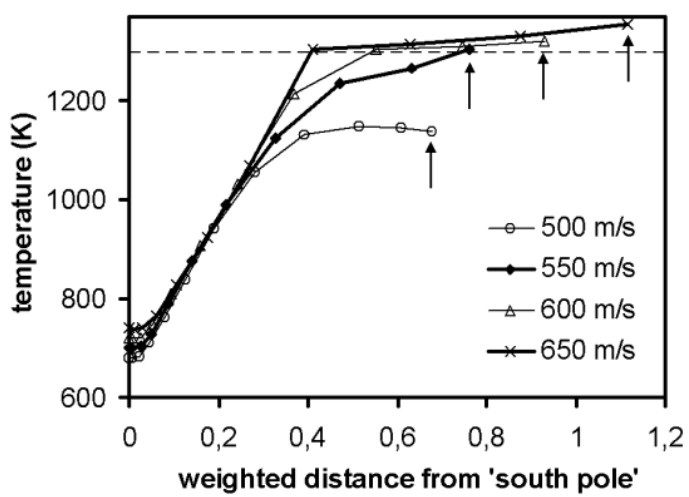

Figure 7. Calculated development of (a) the temperature profiles along a meridian path on a copper particle impacting onto a copper substrate, and (b) the corresponding areas of shear instability at the particle/substrate interface, for different impact velocities [51]. The dashed line in (a) indicates the threshold of the area shear instability, while the arrows indicate the outer rim of the contact zone. The weighted distance in (a) is the square root of the respective inscribed contact area normalised with reference to the initial particle surface area.

Several other studies have used FEM to investigate particle impact and deformation under various impact conditions and material combinations [45, 52-58]. Most of these studies are based on Lagrangian formulation implemented in commercial software. A general feature in Lagrangian-based FEM (L-FEM) simulations is that they can demonstrate ASI at the particle/substrate interface at high impact velocities. L-FEM is also considered to be computationally more efficient. Nevertheless, L-FEM can be associated with excessive mesh distortion and hence unrealistic development of the deformation pattern. This problem does not exist in Eulerian-based FEM (E-FEM), which offers a more realistic account of the deformation geometry, Fig. 8. 


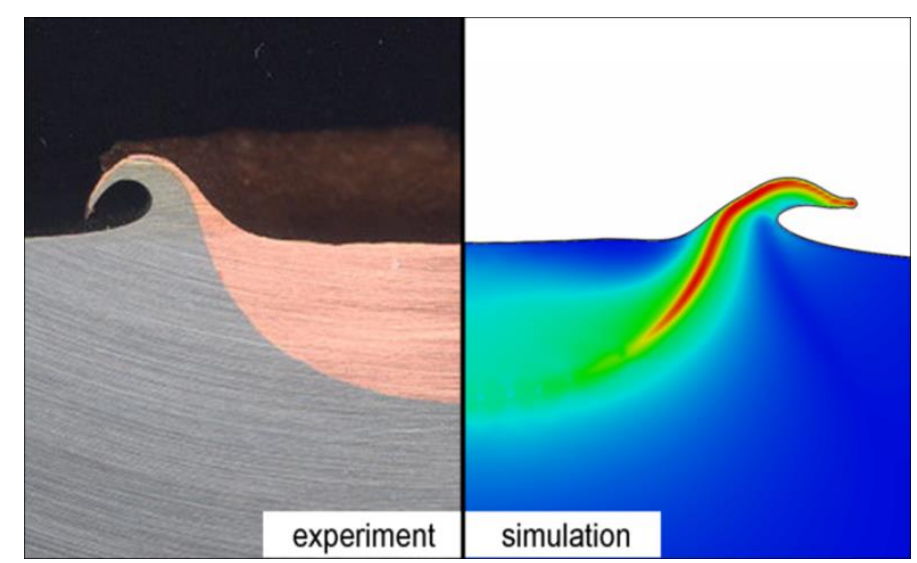

Figure 8. Comparison between large-scale impact experiment [45] and Eulerian-based FEM simulation, for $20-\mathrm{mm}$ copper ball impacted onto a steel substrate at $750 \mathrm{~m} / \mathrm{s}$.

Despite achieving realistic deformation patterns, most of the existing examples of particle impact simulation using E-FEM are in quasi-2D domains and also lack sufficient resolution to show ASI unequivocally. Moreover, definition of surface interaction is not straightforward in E-FEM; by default the respective interacting bodies 'bond' together as soon as they come into contact. Note that continuum-level modelling methods as mentioned above do not directly simulate the process of bonding and rebounding. Instead, they simulate the physical phenomena that relate to bonding, namely plastic deformation and heat transfer. The bonding in standard E-FEM is therefore only artificial. With the implementation of E-FEM in commercial software, nevertheless, this method is again being used more commonly in the study of particle impact in CS (Yu et al. 2012; Yin et al. 2014). Contrary to the initial presumptions, ASI may be appropriately diagnosed in E-FEM [59]. An interesting example of the application of E-FEM to particle impact in CS is the study of the deformation behaviour of oxide films on metallic particles by Yin et al. [56]. Interestingly, the concept of a surface oxide layer may be employed as a basis to simulate bonding and rebounding. Figure 9 shows an example of how this might be achieved. In this way, the bonding and rebounding process are simulated directly, without the need to diagnose ASI. 

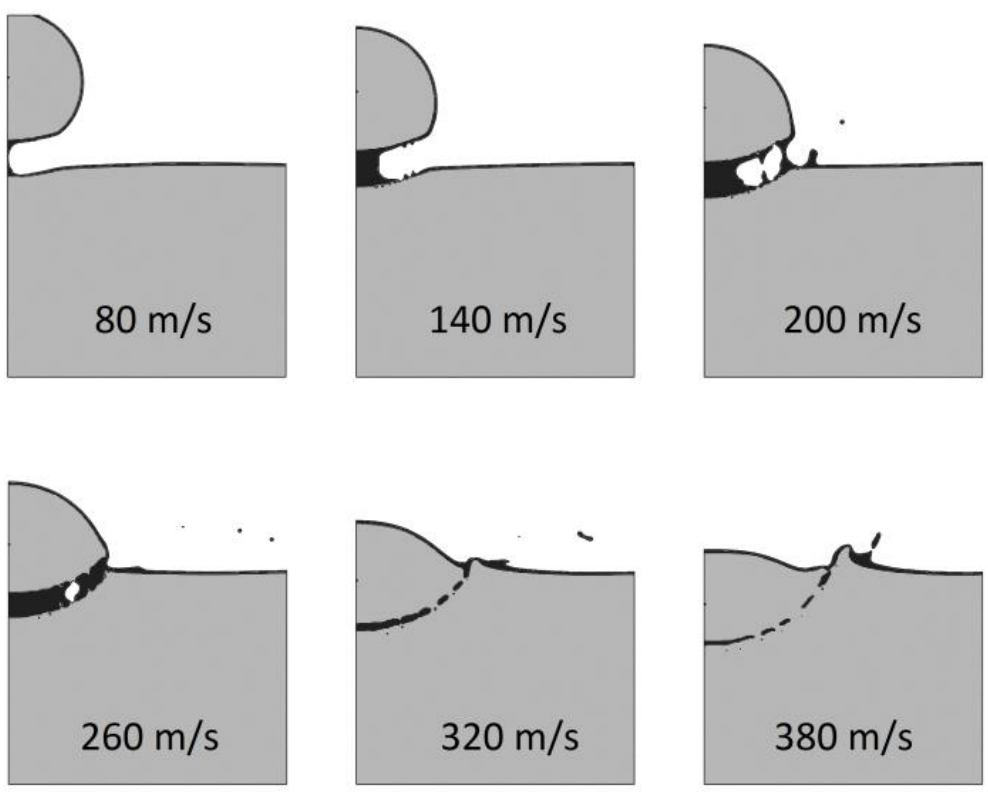

Figure 9. Simulation of bonding and rebounding of superficially oxidised copper particle impacting onto a copper substrate, using Eulerian-based FEM. The oxide layer is described by a pressure-dependent yield model, allowing dilation under tensile stress [245]. The model parameters are set in such a way that rebounding occurs only when the impact velocity is below $260 \mathrm{~m} / \mathrm{s}$, in agreement with the results of large-scale impact tests [45].

Both Lagrangian and Eulerian finite-element methods are mesh-based. There have also been attempts to simulate particle impact using mesh-free methods, such as smoothed-particle hydrodynamics (SPH) and molecular dynamics (MD). SPH is in principle a Lagrangian method in the sense that the nodes move with the material. Examples of application of SPH to cold spray research include the work by Manap et al. [60] and Li et al. [61]. SPH does not have the problems associated with mesh-based methods, but at the price of a generally low spatial resolution. Similar to mesh-based methods, SPH does not simulate directly the process of bonding and rebounding. MD in contrast resolves material deformation on atomistic length scales - and can hence be used to simulate bonding - but it is limited to small domain size, namely to nanoparticles. The few existing examples of simulation of particle impacts using MD are limited to ceramic nanoparticles, i.e. relevant to aerosol deposition [62, 63]. The main objectives in these simulations are: (1) to shed light on the bonding mechanism, and (2) to understand mechanism of deformation in essentially non-deformable ceramic materials. Unlike continuum-level methods, MD is particularly suitable to simulate the process of bonding. Preliminary results of MD simulations show that deformation of brittle materials may be possible through consecutive fracture and bonding, which is associated with grain 
refinement, Fig. 10. Bonding can nevertheless happen only at certain combinations of particle size and particle impact velocity; high velocities or large particles may lead to fragmentation instead of deformation and bonding. There are no indications of ASI or material jetting in the existing MD simulations of particle impact.
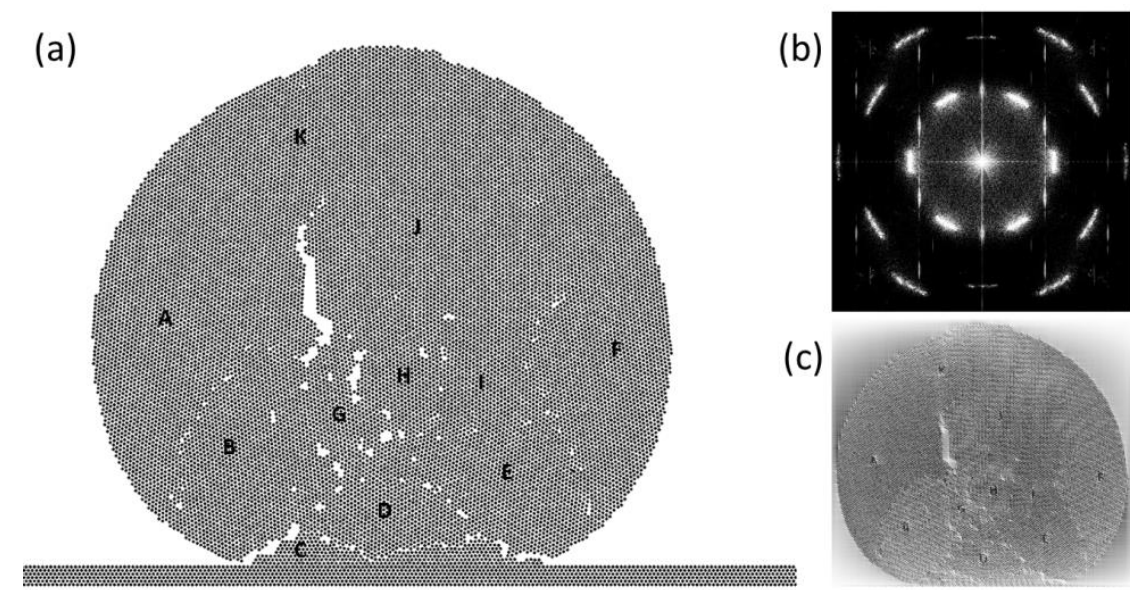

(c)

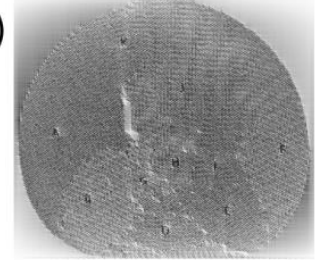

Figure 10. Results of MD simulations for a 35-nm 'brittle' particle impacting a rigid substrate at $375 \mathrm{~m} / \mathrm{s}$, showing (a) snapshot of the atomic positions, (b) Fast Fourier transform (FFT), i.e. 'diffraction pattern' of this, and (c) inverse FFT of a filtered diffraction pattern to make the grain structure more visible [63].

Overall, numerical simulation of particle impact in CS has shown the following important features. For the case of metallic materials, the deformation is highly non-uniform. It may be associated with the occurrence of ASI, which forms initially at the outer rim of the contact zone and extends - with increasing impact velocity - towards the centre. The ASI region never fully covers the contact zone. Moreover, when considering heat transfer, the threshold impact velocity to induce ASI is shown to increase with decreasing particle size. That is, large particles are more prone to ASI. For the case of brittle materials and nanoparticles, deformation may occur through consecutive fracture and bonding. In this case, large particles are more susceptible to to fragmentation.

\subsection{Bonding criteria}

In cold spray deposition, there are two distinct types of bonding that should be distinguished from one another: (i) particle-to-substrate bonding, which is necessary for the formation of the 
first layer of particles, hence relevant for the adhesion strength of the coating to the substrate, and (ii) particle-to-particle bonding, which concerns the build-up of the cold-sprayed deposit, hence relevant for the cohesive strength and physical properties of the deposited material. A major part of the published work on CS focuses on the latter basic question, although there is equally much interest in the former from a practical viewpoint, particularly in applications where coating and substrate materials are dissimilar.

Generally, bonding takes place as soon as atomically-flat clean surfaces of two components are brought into contact. In principle, this can occur without a need for heating, fusion or mechanical interlocking. In practice, however, surfaces of metallic components are rarely flat and are usually covered by an oxide layer. In order to induce solid-state bonding, therefore, the surface oxide layers should be removed or broken up to allow exposure and tight contact of clean metallic surfaces. One way to achieve this is to compress and stretch the interfacial region via plastic deformation, as shown schematically in Fig. 11. As will be discussed below, bonding in CS is conceived to relate to this type of interfacial deformation, which leads to breakup of oxide layers and contact of surfaces at atomic level. Thus, the oxide layer should be considered as a geometrical constraint and not an 'energy barrier' to metallurgical bonding.

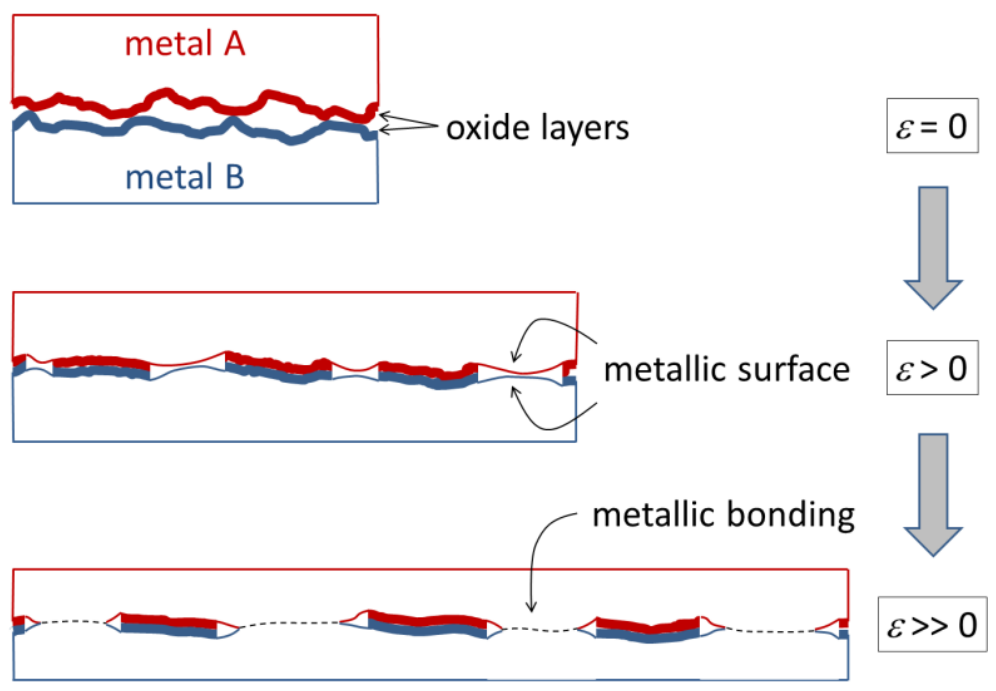

Figure 11. Schematics of interfacial plastic deformation resulting in cold welding. Under high strains, there is contact between fresh metallic surfaces and grain boundaries are formed between the two metals. 


\subsubsection{The role of shear instability}

The results of modelling of particle impact and deformation as discussed in section 3.1 do not directly explain the physics of bonding in CS. Nevertheless, they shed light on the mechanism of interface deformation (Figs 4-6) and oxide breakup (Fig. 9), which are prerequisites for solid-state bonding. As suggested by various researchers, including the inventors of CS [64], the bonding mechanism in CS may be compared to that in explosive welding and magnetic pulse welding. In these processes, bonding takes place as a result of high-velocity impact of two solid objects. A common feature in both processes is the formation and ejection of a material jet, as a result of ASI, at the interface of the interacting bodies, Fig. 12. While shear instability is often associated with shear banding and failure - especially in materials under dynamic loading - it is a key phenomenon that leads to bonding in both explosive welding and cold spraying processes. This is also the case in magnetic pulse welding, which is a close variant of explosive welding.

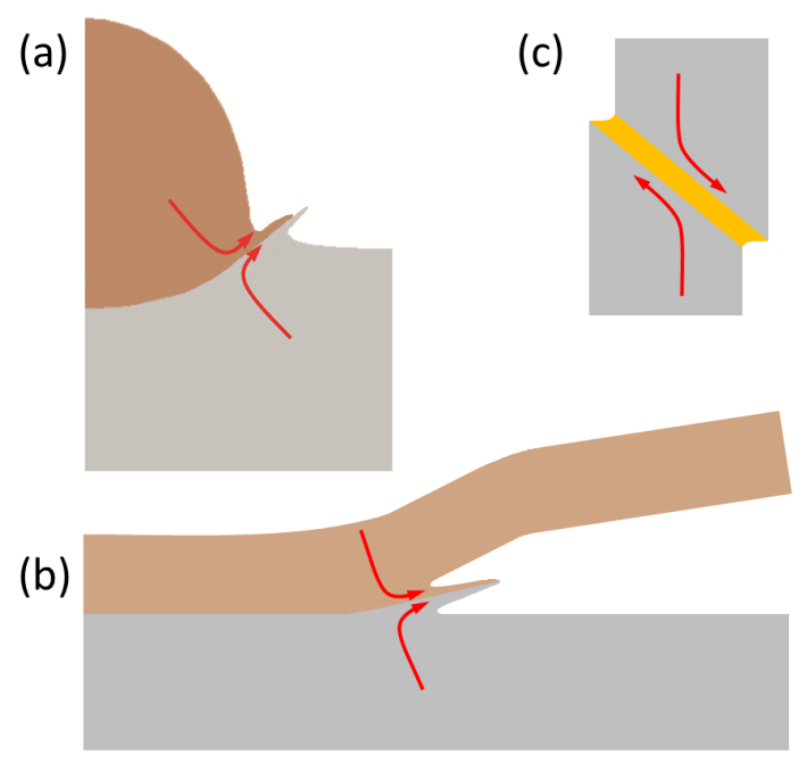

Figure 12. Schematics of deformation localisation due to shear instability in (a) particle impact in cold spraying, (b) explosive and/or magnetic pulse welding, and (c) shear banding under compression. The material flow in (a) and (b) takes place parallel to the surface of the two interacting bodies in the same direction, resulting in jetting and bonding, whereas in (c) shear banding occurs within one component with opposite material displacement, resulting in breakup and failure, as in high-speed cutting. 


\subsubsection{Bonding characteristics in large-scale impact processes}

In view of the role of shear instability and interface deformation in solid-state bonding, explosive welding and/or magnetic pulse welding may be considered as closely-related largescale physical models of CS. Experimental study of bonding characteristics in these largescale processes is relatively straightforward; hence they may be used as experimental bases to understand bonding mechanism in CS of deformable materials. Interestingly, high-velocity impact processes share many common features, regardless of the system dimensions. This is so because in dynamic deformation problems - neglecting the effects of heat conduction and strain-rate hardening - the field variables become unique functions of the length-to-time ratio. In other words, the time-normalised evolution of the deformation pattern becomes independent of the system size for identical impact velocities. The reason for this sizeindependence is explained below from a mathematical point of view.

First, elastic-plastic deformation in dynamic problems may be described by Newtonian equations of motion, where acceleration is proportional to the difference between the applied and the internal force vectors. Second, these force vectors as well as the lumped mass scale with the system dimensions, assuming that the flow stress is not affected by strain-rate hardening and that there is no heat conduction (unlike in Fig 6). Consequently, for any given impact velocity, identical velocity fields will be obtained for adiabatic systems of identical geometrical proportions. This leads in turn to identical displacement and stress fields, if time and spatial dimensions are scaled to the same proportion, Fig. 13.

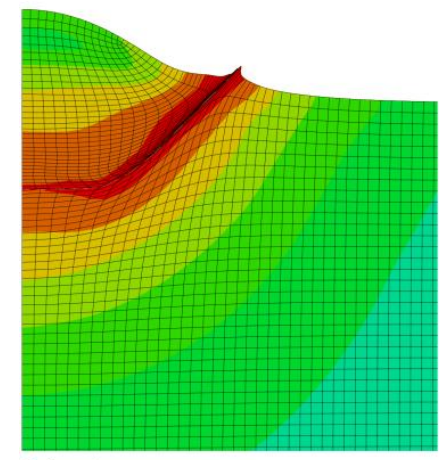

(a) $d_{\mathrm{p}}=50 \mu \mathrm{m}, t=100 \mathrm{~ns}$

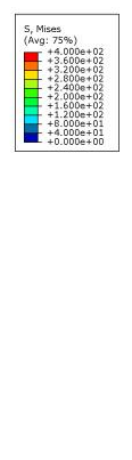

(b) $d_{\mathrm{p}}=50 \mathrm{~mm}, t=100 \mathrm{~ms}$

Figure 13. Lagrangian-based FEM simulation of impact at $400 \mathrm{~m} / \mathrm{s}$ of copper on copper, for (a) diameter of $50 \mu \mathrm{m}, 100 \mathrm{~ns}$ after initial contact, and (b) diameter of $50 \mathrm{~mm}, 100 \mathrm{~ms}$ after 
initial contact. The mesh size in (b) is also 1000 times larger than that in (a). Heat conduction and strain-rate hardening are not considered.

Overall, the relevant factor in impact processes is not the absolute value of the kinetic energy; it is the energy density. The particle size may indeed play a role, but only due to the fact that in smaller systems, strain-rate hardening and conductive heat transfer become more prominent; not because the kinetic energy is smaller. Strain-rate hardening and conductive cooling lead in turn to restricted localised deformation at the interface and less extensive bonding for smaller particles. As mentioned in section 3.1, this type of size effect should be considered for quantitative analysis of ASI during particle impact. Nevertheless, large-scale impact processes can still provide highly relevant albeit qualitative experimental information on the characteristics of the interfacial deformation and bond zones in cold spraying.

Figure 14 shows an example of bond zone microstructure in explosive welding. Based on the elongation of the precipitates in this example, the plastic strain in this region is accurately evaluated to be in excess of $1000 \%$, which is a manifestation of ASI at the contact surfaces. In this example, there is a grain-refined region at the centre of the bond zone. The grain refinement may have resulted from dynamic recrystallization, though it was originally attributed to melting and re-solidification [65]. Similar microstructural features have also been observed in magnetic pulse welding [66]. 


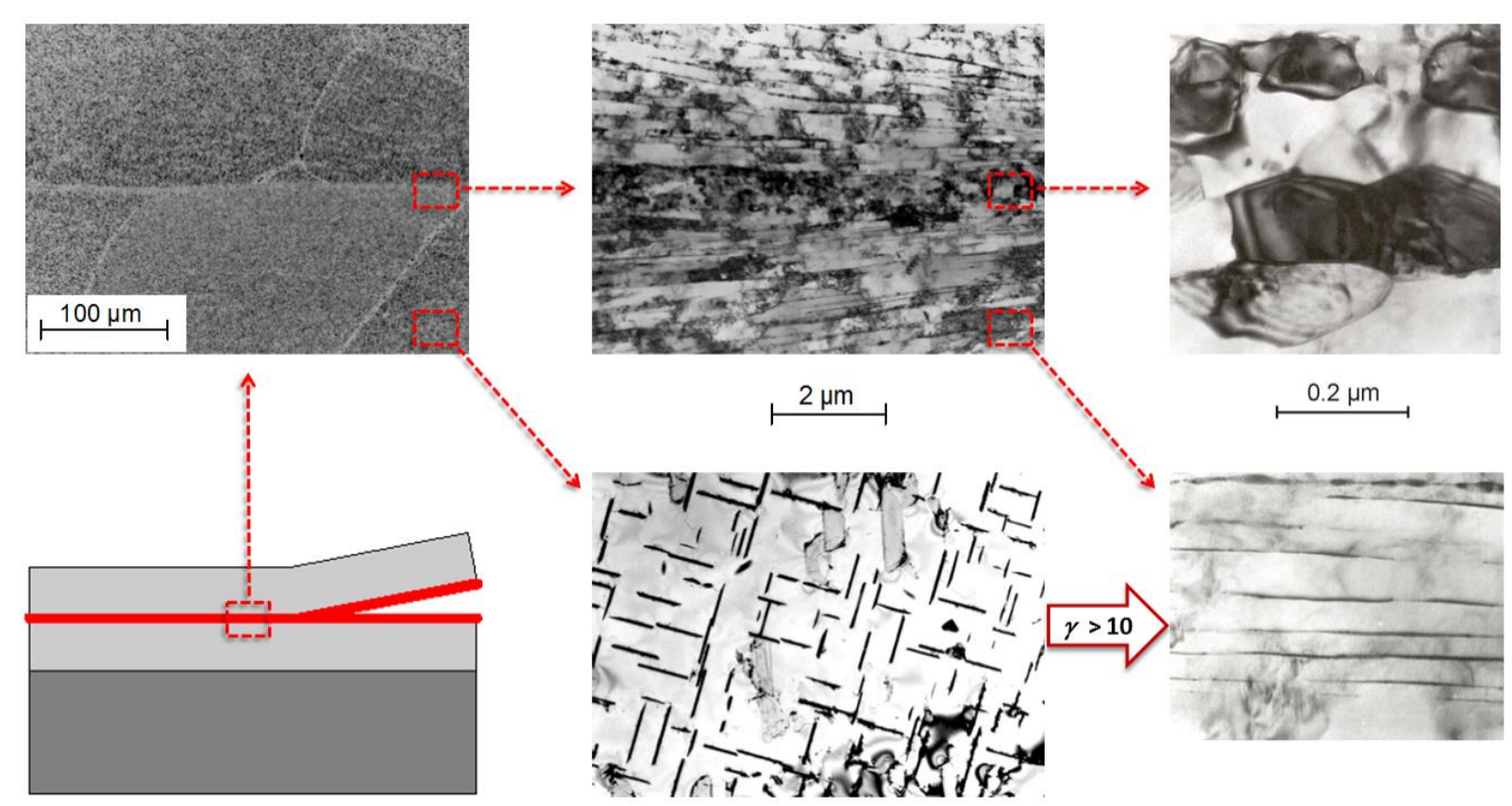

Figure 14. Microstructure of Al-3 wt. \% Cu plates, bonded together using an impact velocity (velocity of the flyer plate in the vertical direction) of $285 \mathrm{~m} / \mathrm{s}$ and an impact angle of $8.6^{\circ}$. The dark acicular precipitates $\left(\theta^{\prime}\right.$ phase $)$ are stretched up to more than 10 times their original length near the bond zone [65]. Equiaxed nanograins are formed at the interface.

In explosive welding bonding takes place for certain combinations of impact angle and impact velocity, Fig. 15. For the case of Al-3 wt. \% Cu plates, bonding occurs only if the impact velocity of the flyer plate is between 200 and $500 \mathrm{~m} / \mathrm{s}$, and the impact angle is within a certain range. The impact angle and the impact velocity determine the velocity of the collision point the point of contact between the flyer plate and substrate - which should be below the speed of sound for successful bonding.

Study of explosive welding thus reveals common characteristics of solid-state bonding due to high-velocity impact, as follows: Bonding (a) occurs above a certain impact velocity; (b) does not occur below a certain impact angle; (c) results from ASI; (d) is associated with large plastic strains of above $1000 \%$; (d) features recrystallization and grain-refinement. The analogy between bonding characteristics in explosive welding and CS has also been considered as a basis to devise laser shock experiments [67] as a micron-scale physical model of particle impact in CS. These experiments resemble explosive welding geometrically, but relate to particle impact in terms of system size. 


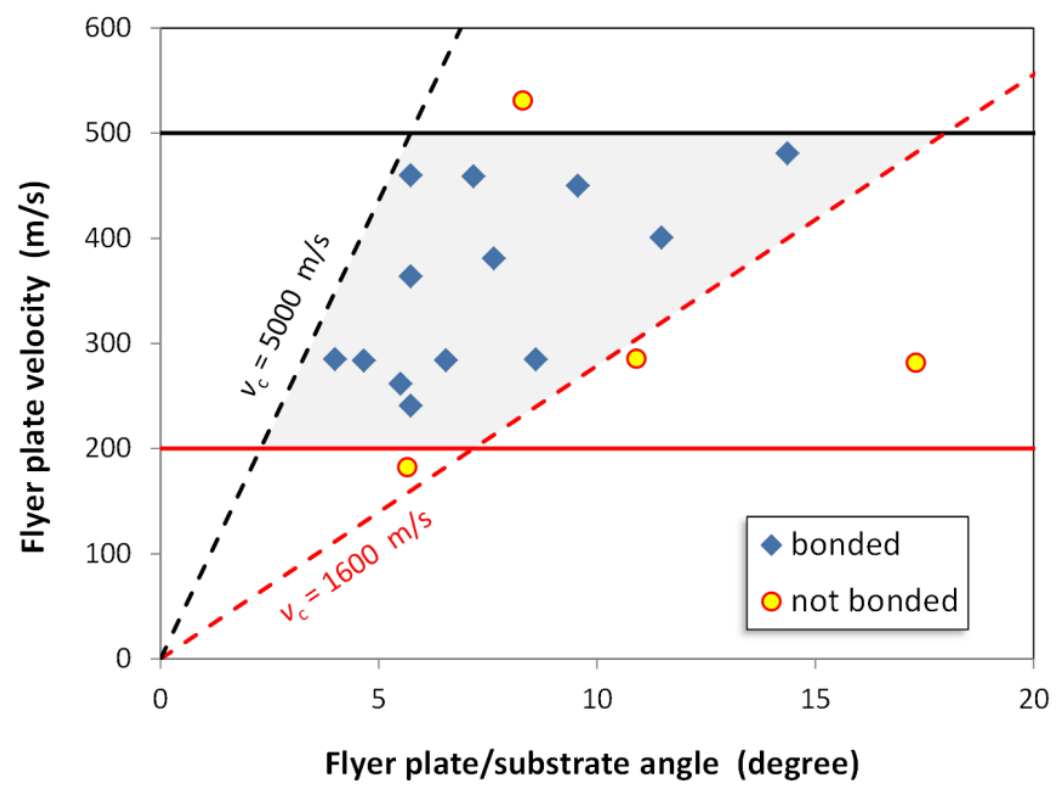

Figure 15. Window of bonding for explosive welding of $\mathrm{AlCu} 3$ plates. The dashed lines correspond to the lower and upper limits of the collision-point velocity, $v_{\mathrm{c}}$, within which bonding is possible. Data are taken from [65].

An alternative large-scale physical model of CS was set up by Schmidt et al. [45], where 20$\mathrm{mm}$ spherical projectiles (balls) were shot onto a substrate using a military gun. As compared to explosive welding, these experiments were geometrically more similar to CS, with the additional advantage that the impact velocity could be accurately measured and controlled. Examples of ball impact tests are shown in Fig. 16. In analogy with the observations in explosive welding, the plastic strain near the interface can be in excess of $1000 \%$, as evaluated considering elongation of grains in the steel substrate. There is also an indication of recrystallization in the copper ball near the interface. The magnitude of strain and the extent of recrystallization depend, nevertheless, on the location in the contact zone; deformation and grain refinement is less prominent at the centre of the contact zone as compared to its periphery. A most important feature is that metallurgical bonding does not occur at the central region of the contact zone - i.e. around the 'south pole' of the particle, the first point of contact with the substrate. No bonding at the south pole of large-scale impact has been verified experimentally - via tensile testing of miniature specimens cut out from different locations over the interface - for copper on copper, copper on steel, and steel on steel [68]. Lack of bonding at the centre of contact zone of the interface is visually evident for the case of copper on aluminium, Fig. $16 \mathrm{~d}$. 


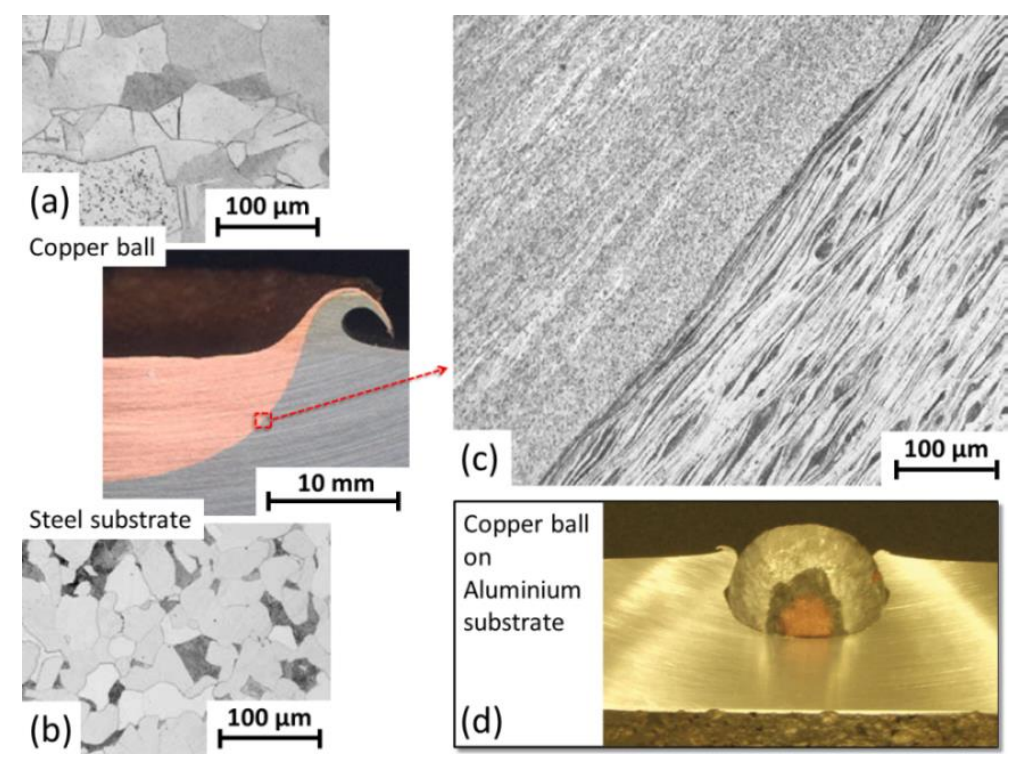

Figure 16. Large impact tests with $20 \mathrm{~mm}$ copper ball shot onto (a)-(c) steel, and (d) aluminium substrates. The grains of steel substrate (b) are elongated more than 10 times (c), and the grains of copper ball (a) are severely refined near the interface [45]. There is no indication of bonding at the centre of impact zone in (d) [140]. The average width of the perspective shown in (d) is approximately $60 \mathrm{~mm}$.

\subsubsection{Bonding of single microparticles}

The impact of single micron-sized particles can be studied by using the so-called 'wipe-test' experiments, where a substrate is rapidly moved in the traverse direction in front of a coldspray jet. These experiments produce samples that are most closely related to real cold-spray deposition, both in geometry and in length scale, though with differences in surface temperature of the substrate. A major downside of wipe-test is that the impact conditions of the deposited particle are never exactly known. Moreover, unlike in explosive welding (Fig. 14) or large impact tests (Fig. 16), experimental evaluation of the plastic strain near the contact region is not feasible. Therefore, ASI and severe plastic deformation of the interfacial region may only be indirectly diagnosed, e.g. in view of features related to jet formation or bonding.

Figure 17 shows examples of such features; they clearly indicate jet formation and bonding during impact of single micron-sized particles. A most prominent feature is that bonding seems to occur initially at the periphery of the contact zone, and that it extends towards the centre as the impact velocity is increased. In agreement with the results of large-scale impact 
tests and simulations, there is no bonding at the central area, e.g. as shown for the impact of Ti6Al4V particles on titanium [69]. Note that the centre of impact is exactly where the hydrostatic pressure reaches a maximum during the impact. This clearly rules out the role of hydrostatic pressure as a main cause of bonding.

The fact that bonding does not occur at the centre of contact zone - both in the impact of 20 $\mathrm{mm}$ balls and in cold spraying of microparticles - agrees well with results of particle impact simulations, Fig. 7. It is also consistent with the results of explosive welding experiments. As shown in Fig. 15, to achieve successful bonding in explosive welding, the flyer plate must collide tilted onto the substrate within a certain range of angles. For the example shown in Fig. 15, there is no bonding below $4^{\circ}$. At parallel or low-angle impacts, shear forces diminish - and also, the velocity of the contact point, $v_{c}$, becomes greater than the speed of sound in the solid material - hence the viscoplastic deformation is suppressed. This leads in turn to the suppression of ASI and jetting. In the impact of spherical objects - be it a 20-mm ball or a 20$\mu \mathrm{m}$ particle - such a condition exists at the centre of the contact zone, where the interacting surfaces are almost parallel. It should be noted that bonding may also occur at the central zone due to frictional dissipation in angular impact [70], but this is not a common feature in CS.

(a)

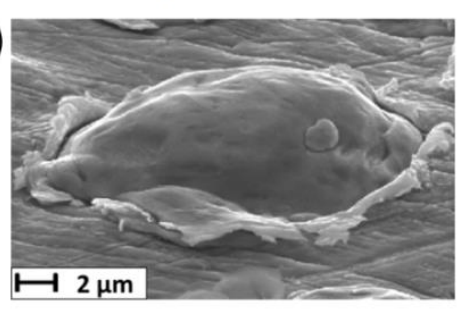

(b)

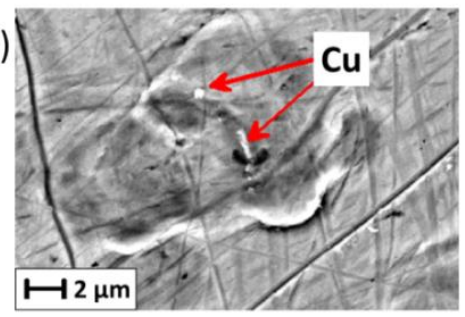

Ti-6Al-4V on Titanium

(c)

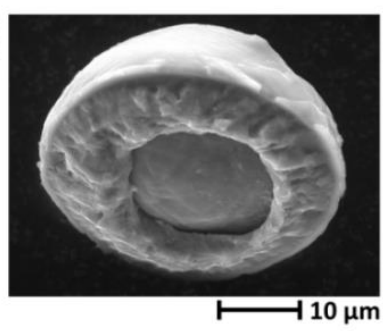

(d)

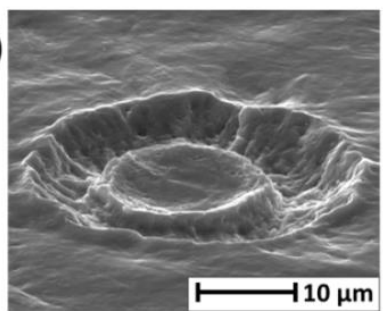

Figure 17. SEM micrographs of single particle impacts in cold spraying, showing (a) jetting [40], (b) residues of a rebounded particle on the substrate at the outer rim of the contact zone [51], (c) residues of substrate on a detached particle (by ultrasonic cavitation), and (d) imprint on the substrate, as a result of impact and detachment of a part of substrate material, related to (c) [69]. 


\subsubsection{Window of deposition for metallic materials}

In view of the above findings, the following conclusions may be drawn on the mechanism of particle-particle bonding in CS of deformable (metallic) materials:

- Bonding is associated with ASI, leading to large plastic strains ( 10) and jetting.

- ASI and bonding occur beyond a certain impact velocity.

- ASI and bonding extend with increasing impact velocity, from the periphery towards the centre of the contact zone, but never cover the entire interface.

Based on these points, ASI may be considered as a prerequisite for bonding in CS of metallic materials [71]. Subsequent studies by various other researchers confirm the role of ASI in bonding. Some studies have underlined the role of interfacial melting in bonding [64, 72-74]. According to these studies, ASI may lead to partial melting for certain combinations of materials and impact conditions [75]. However, there is no consensus on whether or not melting is necessary for bonding; in view of the overall observations, melting does not seem to be a prerequisite for bonding. There has also been a discussion about the role of mechanical contribution, i.e. interlocking [76]. This has nevertheless concerned the bonding between certain combinations of coatings and substrates, and not the general particle-particle bonding as in the build-up of CS deposits. The bonding mechanism has also been discussed in view of the competition between the adhesion and the rebound energy [77-79]. Consideration of the rebound energy seems to be relevant for some cases of materials - such as metallic glasses (see Fig. 20 below) - where the interface is liquefied and hence exhibits little resistance to rebounding. For the case of solid interfaces, however, postulation of 'adhesion energy' may be too simple an approach, as it disregards the role of fracture mechanics and plasticity in particle detachment. Regardless of the perceived mechanism of bonding, there is consensus that bonding occurs beyond a critical velocity, and that this velocity generally decreases with increasing particle temperature. It is also presumed that too high impact velocities result in hydrodynamic erosion of the substrate [45]. The region bound between these two characteristic velocities defines the window of deposition in CS, as shown in Fig. 18. 


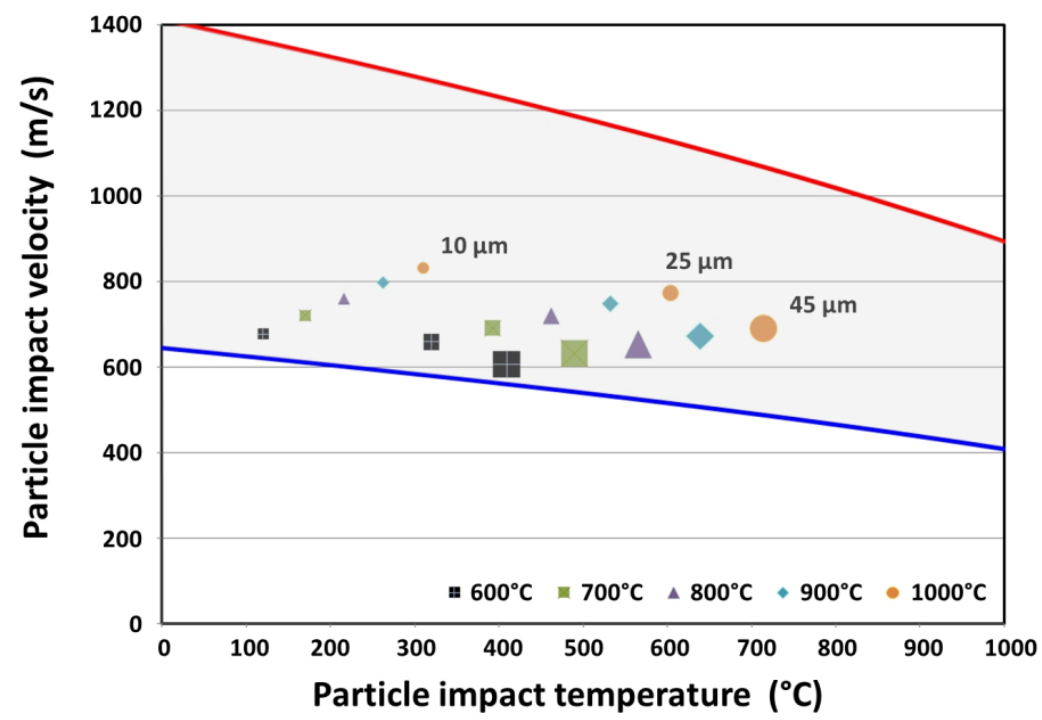

Figure 18. Window of deposition for cold spraying of titanium with nitrogen at 40 bar and different initial gas temperatures as shown in the legend [59]. The extent of ASI is increased by exceeding further away from the critical conditions for bonding (lower bound of the grey region). Note that the particle temperature is always lower than the initial gas temperature (more prominently so for smaller particles).

\subsubsection{Bonding of dissimilar materials}

All of the above experiments and conjectures concern bonding between two similar metallic materials of relatively high deformability. The problem complicates further for the cases where bonding is between two different metals or between metal and ceramic.

For the case of dissimilar coating/substrate materials, the bonding characteristics and hence the adhesion strength depend on the differences in properties - mainly hardness and density of the respective materials. As a rule of thumb, smaller differences in properties results in better bonding. If the substrate is softer and less dense than the impinging particles, the particles may penetrate more deeply, resulting in the dissipation of the kinetic energy over a longer time and over a larger volume of the substrate material. This leads to diminished particle deceleration and 'impact power' (see section 5.3), hence suppressed ASI on the particle side. A large-scale example of this case is shown in Fig. 14d. Despite suppression of the ASI and metallurgical bonding in this case, the coating may still exhibit good adhesion to the substrate, arguably because of mechanical interlocking. This is not the case when the 
substrate is harder than the particles, as there would be neither sufficient metallurgical bonding nor mechanical interlocking. On the other hand, metallic materials have been successfully deposited on ceramics, and even on glass [80]. It is clear that ceramics do not deform plastically, so that bonding cannot be explained based on the ASI conjecture. Also, mechanical interlocking would not be a viable option. It is therefore not completely clear how metal coatings bond to ceramic or glass substrates. There have been studies of the interface between aluminium coating and ceramic substrates [81, 82]. It has been argued that mechanical interlocking is not necessary for bonding for such cases, and that adhesion is influenced by structural match on the atomic scale [82].

Dissimilar material bonding is also relevant for CS of powder blends to produce composite deposits. In this case, also, similar properties of the powder materials would lead to better bonding. This is nevertheless rarely aimed for, as composites are intentionally produced from materials of often drastically different properties. Fortunately, successful deposition is possible, if at least one of the constituents has sufficient ductility to embed the other. In this case, bonding between soft and hard particles would not be a critical issue, as long as there is sufficient bonding between the soft embedding particles. Clearly, this works out only if the volume fraction of the hard constituent is below a certain limit.

\subsubsection{Bonding of brittle materials}

A broader question concerns the mechanism of bonding for intrinsically brittle materials, such as ceramics, metallic glasses and WC-metal composites (cermets). Ceramic materials have been successfully deposited by aerosol deposition or vacuum cold spraying. Also, highpressure CS has been used for the deposition of metallic glasses. Despite successful experiments, CS of brittle materials is yet to be fully explored. For the case of ceramic materials, initial theoretical investigations using molecular dynamics (discussed above) indicate that deposition is possible between two limiting impact velocities, Fig. 19. 


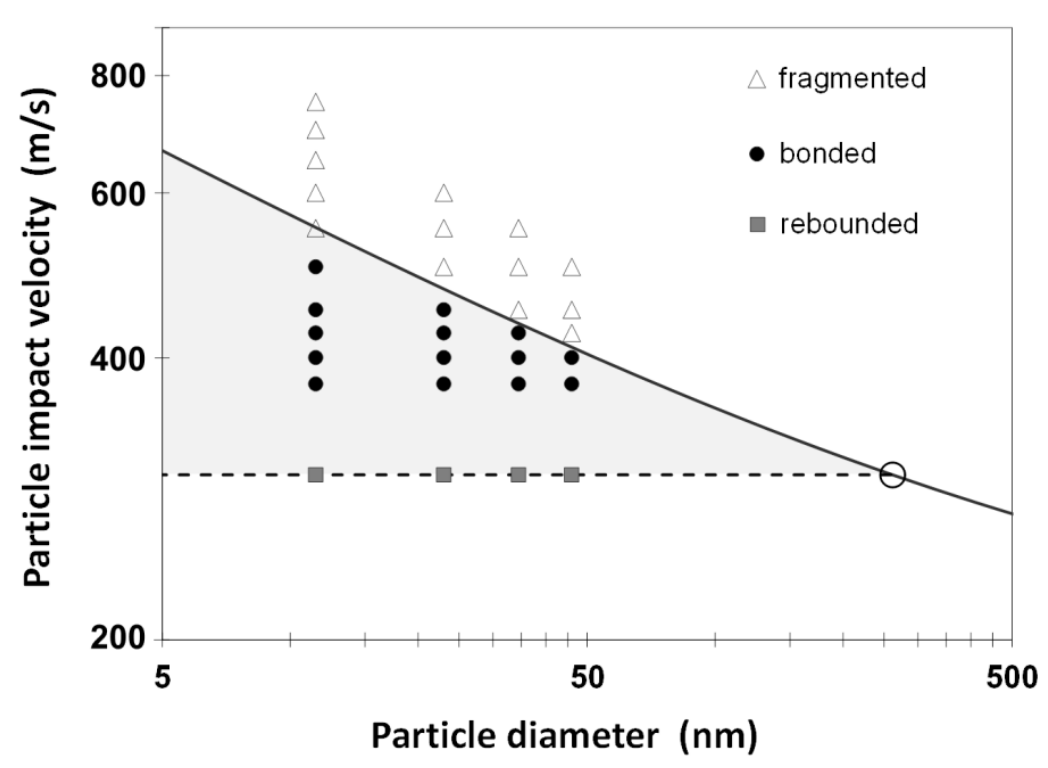

Figure 19. Window of deposition for simulation of impact of brittle nanoparticles [63].

In addition, deposition of ceramics by $\mathrm{AD}$ seems to be viable only when the particle size is below a certain limit. The role of particle size is also evident in CS of ceramics and cermets. In both cases, deposition has been successful only when agglomerates of small particulates with certain levels of porosity were used. There is so far little information on the mechanism of deformation and bonding of such agglomerates.

Bulk metallic glasses (BMGs) may also be classified as intrinsically brittle materials. Nevertheless, metallic glasses exhibit different modes of deformation based on the temperature, loading conditions and even geometry [83]. The deposition mechanism of metallic glasses is equally complex and not yet fully understood. Some features in bonding and deposition of metallic glasses by CS are discussed below.

Study of individual splat morphologies indicates a mixture of shear banding and localised viscous flow throughout the particle. There is also interface softening as a result of ASI, similar to that in crystalline materials $[84,85]$. A presumption is that the particle temperature should be above $T_{\mathrm{g}}$, allowing for viscous flow of the material in the undercooled liquid state [86]. Recent investigations on $\mathrm{Fe}_{73} \mathrm{Cr}_{2} \mathrm{Si}_{11} \mathrm{~B}_{11} \mathrm{C}_{3}$ attributes successful deposition to viscous flow at high $\left(>10^{-3}\right)$ Reynolds numbers $[87,88]$. This interpretation cannot explain experiments using helium as process gas, where particles cool down to temperatures below $T_{\mathrm{g}}$. Impact temperatures have been estimated to be $130-340{ }^{\circ} \mathrm{C}$ for $\mathrm{CS}$ of NiTiZrSiSn or 
$\mathrm{Zr}_{55} \mathrm{Al}_{10} \mathrm{Ni}_{5} \mathrm{Cu}_{30}$ with helium $[16,84,85]$, well below the respective glass transition temperatures. It has been argued that the temperature may rise locally at the particle-substrate interface [89]. The temperature may indeed rise locally to very high values in BMGs due to shear banding $[83,87]$. On the other hand, as a precursor to shear banding, disorder by deformation may be responsible for local strain and strain-rate softening of metallic glasses $[90,91]$. It is not yet clear which mechanism plays a more dominant role in cold-spray deposition of BMGs.

Despite the very short exposure of particles to the gas stream (about maximum $0.003 \mathrm{~s}$ ), a significant amount of the originally amorphous structure may crystallize at increased gas temperatures. The crystallization mostly occurs at the particle-particle interfaces, as shown by TEM investigations $[89,92,93]$. This is because of exceeding the corresponding crystallization temperature, $T_{\mathrm{x}}$, and the incubation time [87]. To verify this, one would need to work out the thermal history of the interfacial region [89, 92], which is determined by the interplay between the heat conduction and the heat generation by deformation. Such an analysis is complicated becuase the incubation time for crystallization decreases drastically with increasing strain rate $[94,95]$.

Interestingly, the deposition efficiency of BMGs passes through a maximum by increasing the process gas temperature or pressure $[87,96]$. More severe process conditions lead to particle detachment and rebound $[97,96]$. An example of partial detachment of a particle is shown in Fig. 20. Detachment occurs whenever the interface is liquefied $\left(T>T_{\mathrm{g}}\right)$ and so, cannot withstand the rebounding elastic forces. Successful deposition occurs only if the interface cools down fast enough, so that the viscosity increases to sufficiently high values, or the temperature falls below $T_{\mathrm{g}}$. This conjecture has been experimentally verified, by demonstrating lower deposition efficiencies attained on preheated substrates [96].

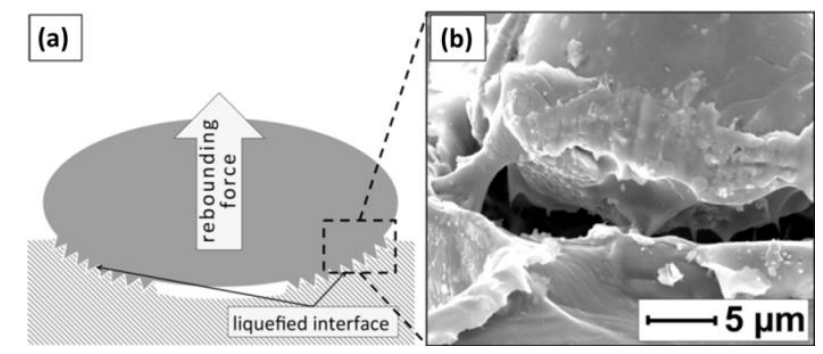

Figure 20. Example of particle rebounds and interface separation during cold spraying of amorphous $\mathrm{Cu}_{50} \mathrm{Zr}_{50}$ particle; (a) schematics, and (b) SEM of partial detachment [96]. 


\subsection{Quantification of the critical condition for bonding}

The critical velocity for bonding in CS can be evaluated experimentally, by correlating the (measured or calculated) particle impact velocity with the measured deposition efficiency (DE) of the corresponding powder [27]. It can also be estimated through numerical simulation of particle impact, considering that the threshold of bonding and ASI occur at the same particle impact velocity [40]. Moreover, the following expression has been used to fit the evaluated critical velocities for identical coating/substrate material [45]:

$$
v_{\mathrm{cr}}=\sqrt{a \sigma / \rho+b c_{p}\left(T_{\mathrm{m}}-T_{\mathrm{p}}\right)}
$$

where $\sigma$ is the temperature dependent flow stress, $\rho$ is the density, $c_{p}$ is the heat capacity, $T_{\mathrm{m}}$ is the melting temperature, $T_{\mathrm{p}}$ is the mean temperature of particle upon impact, and $a$ and $b$ are fitting constants. A good fit for powders of typical particle size distributions is obtained when $a=4$ and $b=0.25$. The temperature-dependent flow stress can be approximated as follows:

$$
\sigma=\sigma_{\mathrm{UTS}}(1-\theta)
$$

where $\theta$ is the normalised temperature as in Eq. (1). The equation assumes a linear softening of the material up to the melting temperature. The critical velocity is also found to be a function of particle size, namely increasing with decreasing particle size. This size dependence of the critical velocity has been attributed to the role of heat conduction [45] and accordingly formulated as a function of adiabaticity [98]. The size-dependence of critical velocity has been worked out and verified experimentally for copper. The size dependence for nickel has been estimated using FEM simulations [99].

Prediction of the critical velocity and its dependence on particle size has also been estimated through alternative criteria for bonding. Examples of alternative criteria for bonding include those based on the adhesion energy and rebound energy [100], and on the evolution of maximum plastic strain, as worked out by E-FEM simulations [101]. Moreover, the critical velocity has been shown to be influenced by surface oxidation of the particles of the feedstock [102-104]. Higher surface oxidation normally results in increased critical velocity. Clearly, smaller particles are more affected by surface oxidation, because of their larger surface to volume ratio. Thus, surface oxidation should be considered as a factor in the study of size- 
dependence of the critical velocity, in addition to that relating to adiabaticity. Further work is needed to refine the analytical basis for the prediction of the critical velocity, for instance, to include the effect of oxide layer, non-linear thermal softening behaviour, or the effect of substrate material properties.

Considering the role of particle temperature in bonding, Fig. 18, one may equally think of a 'critical temperature' for bonding. That is, at a fixed impact velocity, increasing particle temperature beyond a certain value will result in bonding. Alternatively, the critical condition for bonding may be formulated in terms of the overall energy of the particle upon impact, as described below. It should be stressed nevertheless that the following formulation does not include new theoretical analyses; it is only a rewriting of the above criterion for bonding in terms of newly defined parameters. The total energy per unit mass of a particle can be considered to be the sum of two parts, the kinetic energy and a nominal thermal energy, as follows

$$
E=E_{k}+E_{\text {th }} \text { where } E_{k}=\frac{1}{2} v_{p}^{2} \text { and } E_{t h}=c_{p}\left(T_{p}-T_{\text {ref }}\right)
$$

Note that the nominal thermal energy as defined here is different from the real thermal energy, in that it disregards the latent heat of fusion at temperatures higher than $T_{\mathrm{m}}$. At the critical impact condition for bonding, the following relations hold:

$$
\begin{gathered}
\left.E_{t h}\right|_{c r}=E_{t h}^{0} \theta, \text { where } E_{t h}^{0}=c_{p}\left(T_{m}-T_{\text {ref }}\right) \\
\left.E_{k}\right|_{c r}=E_{k}^{0}(1-\theta), \text { where } E_{k}^{0}=\left(a \sigma_{\mathrm{UTS}} / \rho+b E_{t h}^{0}\right) / 2
\end{gathered}
$$

where $a$ and $b$ are the same calibration factors as in Eq. (3). The reference thermal energy $E_{t h}^{0}$ may be interpreted as the minimum thermal energy of particle required for bonding at zero kinetic energy. Likewise, the reference kinetic energy $E_{k}^{0}$ may be interpreted as the minimum kinetic energy of particle required for bonding at zero thermal energy. Thus, Eq. (6) is nothing more than a rearrangement of Eq. (3), in which $E_{k}^{0}$ is simply $\frac{1}{2} v_{c r}^{2}$ at $T_{p}=T_{\text {ref }}$. In view of these considerations, a dimensionless energy-based deposition parameter can be defined as follows:

$$
\eta_{E}=\bar{E}_{k}+\bar{E}_{t h} \text { where } \bar{E}_{k}=E_{k} / E_{k}^{0} \text { and } \bar{E}_{t h}=E_{t h} / E_{t h}^{0}
$$


In fact, $\eta_{E}$ may be considered as a general characteristic parameter for both thermal and cold spraying, and the necessary condition for deposition can be expressed as:

$$
\eta_{E} \geq 1
$$

A property of the above criterion for deposition is that it does not concern the question of exceeding a critical velocity; instead, it concerns exceeding a critical normalized energy content. Based on this, the window of deposition can be plotted on an energy diagram, where the critical conditions are signified by a straight line, connecting $E_{t h}^{0}$ and $E_{k}^{0}$ on the corresponding axes, Fig 21.

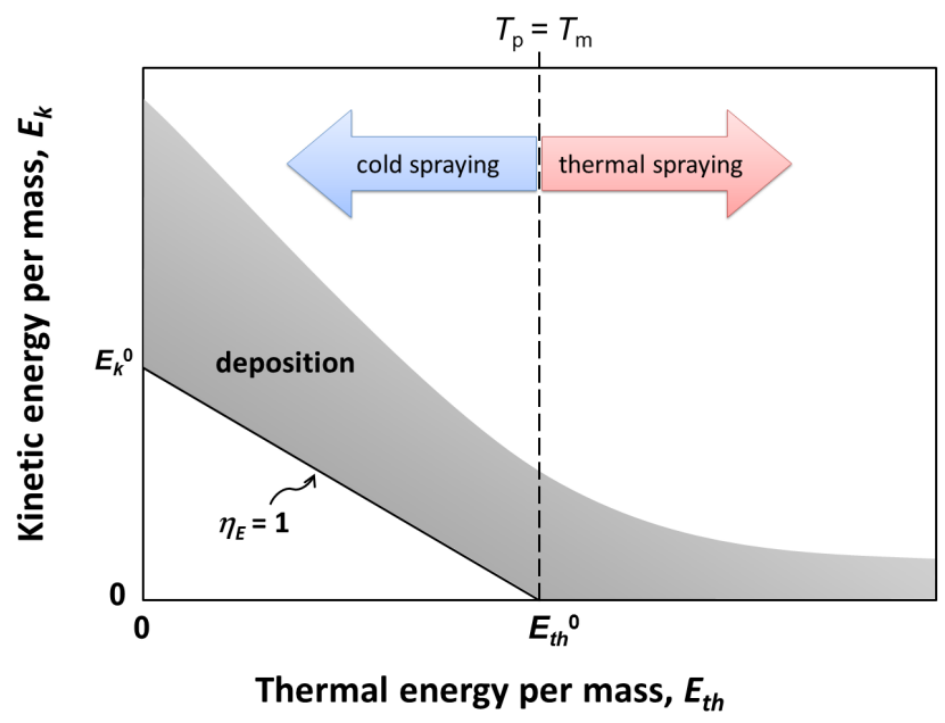

Figure 21. An energy-based representation of the window of deposition based on equations (5) to (8). Deposition takes place when the normalised energy content, $\eta_{E}$, is above unity, i.e. it falls in the grey region. In this region, contours of constant $\eta_{E}$ would be straight lines parallel to the lower bound, i.e. $\eta_{E}=1$. The upper bound of the deposition window is sketched schematically to mark the threshold of hydrodynamic material removal or splashing away of droplets at too high impact velocities.

The postulation of the energy parameter is different from that of the velocity ratio $\eta=v_{p} / v_{c r}$ [98], in that the two components of energy in $\eta_{E}$ are normalised individually. This means that there is no unique critical energy for bonding. However, it can be shown that the following relationship exists between the normalised energy parameter and the velocity ratio: 


$$
\eta_{E}=\eta^{2}(1-\theta)+\theta
$$

The above relationship implies that at higher particle temperatures, the energy parameter becomes independent of the velocity ratio. Likewise, the energy parameter correlates well with the velocity ratio at lower temperatures.

\section{Deposit characteristics}

CS should be considered both as a coating method and as an alternative to conventional AM for the production of bulk components. Therefore, the relevant deposit properties concern both standard coating properties, such as adhesion strength, and the common bulk properties. Examination of various properties of cold-sprayed deposits shows that in many cases there is a unique correlation between the property and the normalised impact velocity, $\eta=v / v_{c r}$ [98]. This is shown, as an example, for copper in Fig. 22.

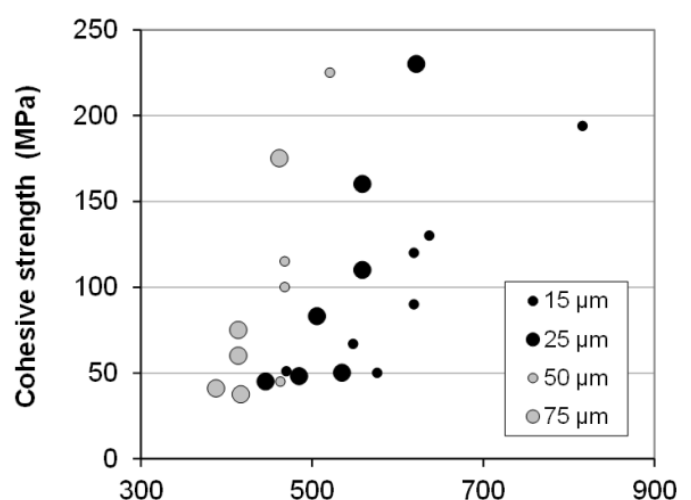

(a)

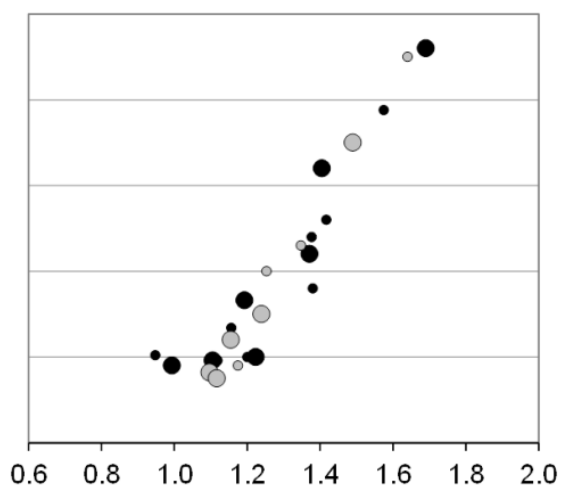

(b) $\quad \eta=v_{p} / v_{c r}$

Figure 22. Tensile (cohesive) strength of cold-sprayed copper coatings as a function of (a) particle impact velocity, and (b) ratio of particle impact velocity to the critical velocity [98]. There is a unique correlation between the cohesive strength and the velocity ratio, regardless of the particle size and spraying conditions.

It should be noted that the correlation between properties and velocity ratio is not universal, and that it is best applicable to low particle temperatures. For instance, near the melting temperature the critical velocity approaches zero and hence the velocity ratio becomes infinitely large. At higher temperatures, therefore, the data might be better interpreted in view 
of the energy parameter, Eq. (7). This needs to be explored in future work. In any case, interpretation of cold-sprayed deposit properties can be discussed conveniently in view of these normalised velocity or energy parameters.

On a microscopic level, properties of cold-sprayed deposits are inherited from their microstructure and state of deformation. Generally, cold-sprayed deposits that are produced under optimum conditions exhibit microstructures and properties similar to those of highly cold worked bulk material, e.g. high yield strength and low elongation to failure. Moreover, high densities of lattice defects restrict electron mobility and thus degrade conductivity. The same applies to the central regions of the particle-particle interfaces, which are not metallurgically bonded. The non-bonded interfaces also act as crack nuclei under tensile loading. Further to these structural deficiencies, the shot-peening effect (due to particle impact) combined with thermal misfit may result in complex residual stress profiles. These unfavourable effects can be alleviated by appropriate post heat treatments, or by substrate preheating, to induce recovery and recrystallization. A brief discussion of the microstructures and properties of cold-sprayed deposits are given below.

\subsection{Microstructure}

There are three important microstructural features that are commonly found in most coldsprayed deposits: (1) severe plastic deformation as signified by a high density of dislocations and other defects, (2) grain refinement due to dynamic recrystallization, particularly near the interfaces, and (s) non-bonded interfaces, namely at the centre of impact zones. These features appear to be common not only in cold spraying, but also in the closely-related process of warm spraying [105]. Another aspect of cold-sprayed microstructures is that they are highly anisotropic [106]. Properties of cold-sprayed deposits are to a large extent influenced by these features. Figure 23 shows an example of the microstructure of cold-sprayed copper, showing various types of lattice defects near a particle-particle interface. 


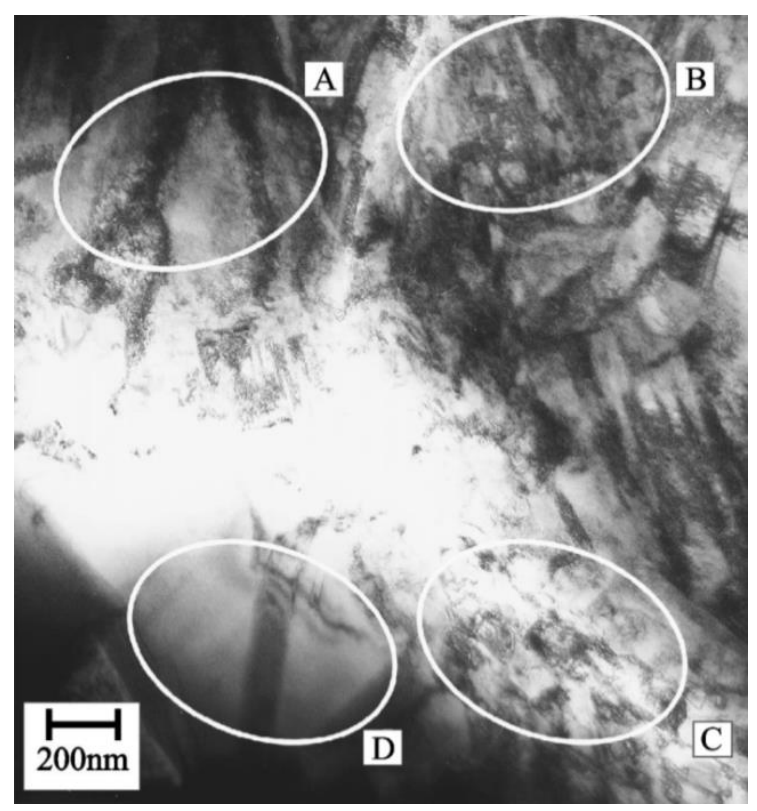

Figure 23. TEM micrograph of a cold-sprayed copper coating, showing various microstructural features, including (A) dislocations walls, (B) elongated nanograins, (C) equiaxed nanograins, and (D) a micron-sized dislocation-free grain containing twins [107].

Dislocations are among the most prominent defects in cold sprayed deposits. They can be homogeneously distributed or pile up into dislocation walls. Moreover, dislocations can form persistent nano-sized loops that do vanish by annealing, with implications on the mechanical and electrical properties of the deposit [108]. The density of dislocations can be different from one material to the other; e.g. it is normally higher for aluminium as compared to copper and nickel [109], presumably due to differences in the stacking fault energy. On the other hand, the dislocation density can be very low in nanograins of aluminium alloys that are already nanocrystalline before spraying [110]. This is regarded as a common feature in the deformation of nanocrystalline materials.

An example of electron backscatter diffraction (EBSD) maps of cold-sprayed copper is shown in Fig. 24. The figure shows regions of highly deformed materials near the particle-particle interfaces, but also a relatively high amount of misorientation within the particles. In the image quality (IQ) map the grey level correlates roughly with the severity of plastic deformation and lattice defects. Moreover, the bright streaks (green in the colour version) in the kernel average misorientation (KAM) map correspond to rotation gradients, which correlate roughly with the density of GNDs. Note that the grains in the upper-left of the maps appear to be free of misorientation, possibly indicating recovery or (static) recrystallization. 
This is consistent with the dislocation-free region as observed in Fig. 23. There are several examples of analysis using EBSD in the literature, e.g. for cold-sprayed copper [111] and aluminium [112]. Moreover, electron channelling contrast imaging (ECCI) has been used in the study of grain structure and defects in cold-sprayed deposits; see e.g. [113,114].

Nanoscale twinning has also been observed in cold-sprayed nickel [115].

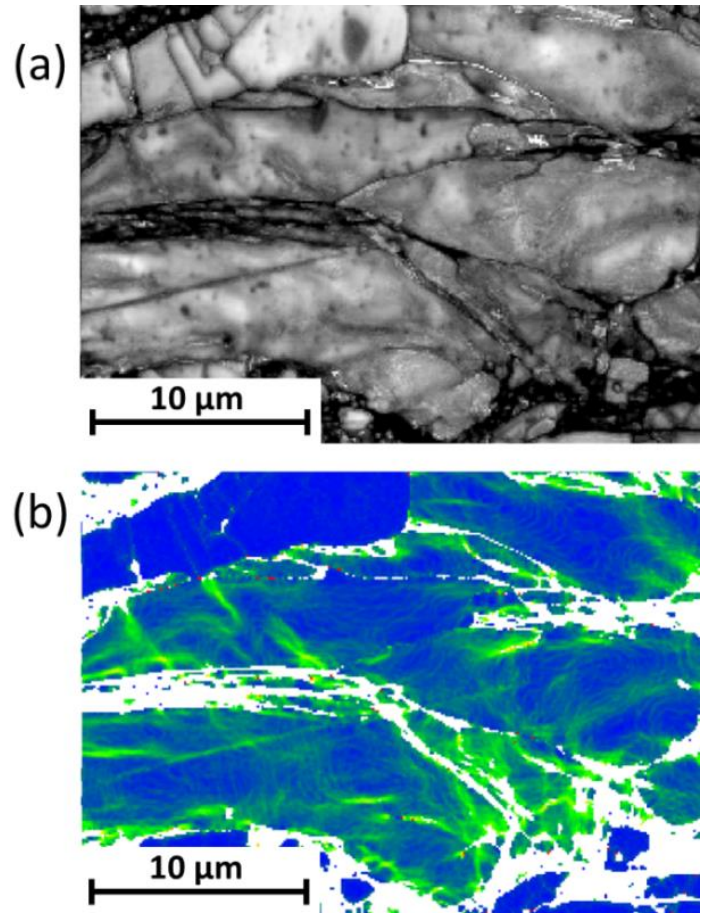

Figure 24. EBSD maps of the cross section of a cold-sprayed copper coating, showing (a) image quality map and (b) kernel average misorientation (KAM) map (courtesy of Tom Jäpel, Max Planck Institute for Iron Research, Düsseldorf, Germany).

Detailed studies of the cross section of interfaces in cold-sprayed deposits indicate grain refinement due to dynamic recrystallization, e.g. as observed in zinc [116], titanium [117] and aluminium [118]. TEM studies have revealed no bonding at the central zones, e.g. as observed in cold-sprayed titanium [119]. Microstructural studies of cold-sprayed deposits also include extensive FIB/TEM analysis of the particle-particle and particle-substrate interfaces, e.g. by Kang et al. [103]. These studies particularly focus on the role of surface oxide layers in CS, but also provide concrete evidence for dynamic recrystallization at the interfacial regions.

Recrystallization is often associated with the formation of nanostructures [120-122]. However, the extent and distribution of nanograins depend on the material; e.g. being less uniform in nickel as compared to copper [123]. This may be attributed to differences in 
activation energies for recrystallization or to the differences in local temperatures due to different thermal conductivities of copper and nickel. In the cases where the starting material is already nanostructured, the nanocrystalline structure is often retained after CS, e.g. as observed in a cold-sprayed Al-Mg alloy [110]. There have also been reports of dynamic amorphization in Al-Al, Ni-Al [124], $\mathrm{Al}-\mathrm{Cu}$ [125], $\mathrm{Cu}-\mathrm{Ni}$ [126], $\mathrm{Al}-\mathrm{Mg}$ [127] and $\mathrm{Fe}-\mathrm{Al}$ $[128,129]$ systems, over a layer of up to tens of nanometres thickness. For the case of metallic glasses, on the other hand, CS may result in nanocrystallisation of the initially amorphous phase [89]. More examples of amorphization and dynamic recrystallization in cold-sprayed deposits are reported in the literature [124,130-132].

It is a common notion that CS is particularly suitable for applications where a phase change is to be avoided. Incidentally, CS can bring about structural changes and phase transformation that are hardly attainable by any other method. This is so because of the severe plastic deformation at high strain rates of up to $10^{9} \mathrm{~s}^{-1}$, combined with high pressures of up to more than $10 \mathrm{GPa}$ and extremely high cooling rates. These changes include formation of metastable microstructures, in addition to nanocrystallisation and amorphization; see e.g. the review by Luo et al. [133]. In some cases, the reverse may happen. That is, the impact can result in deformation-induced transformation of an initially metastable phase into a more stable state, e.g. bcc to fcc in steel 316L [134] and in MCrAlY [135].

\subsection{Mechanical properties}

Mechanical properties of cold-sprayed deposits are much influenced by the density of lattice defects, the non-bonded areas, and the often severe change in the grain size. For instance, nanoindentation of cold-sprayed titanium has shown a correlation between grain size and hardness, following a Hall-Petch relationship [114]. Another important property of cold-spray deposits is the general lack of ductility due to severe deformation, though this can be improved by heat treatment [136-138]. Heat treatments can result in recovery and recrystallization of the material, and also increase the extension of bonded interfaces. In theory, partial recovery and recrystallization may occur during spraying of some materials, resulting in some levels of ductility. This is consistent with the observation of dislocation-free regions in as-sprayed copper samples, Figs 23 and 24. The role of non-bonded interfaces in the mechanical behaviour of cold-sprayed deposits can be explained as follows. For every 
bulk material there is a relationship between hardness and tensile strength. In cold-sprayed deposits, however, there is often a deviation from this relationship, indicating different plastic behaviour and strength under tension and compression. Differences in tensile and compressive strengths normally indicate the presence of discontinuities and cracks in the material. Deviations from hardness-strength relationships have been observed for copper [139] and for nickel [140]. These deviations can be minimised by using optimum spraying conditions, leading to close-to-bulk mechanical behaviour of the cold-sprayed deposits [140].

Despite the lack of ductility, both the cohesive and adhesive strengths of cold-sprayed coatings can be rather high. For instance, adhesion strengths of up to $120 \mathrm{MPa}$ have been reported for thick copper coatings sprayed on steel substrates [141]. In a similar case, using extreme spraying conditions and He as process gas, this has been reported to be as high as 200 MPa [142]. For these measurements, special testing methods have been used, since the standard methods using glue is limited to adhesion strengths of up to about $80 \mathrm{MPa}$.

\subsection{Residual stress}

It is a common presumption that cold-sprayed coatings have compressive residual stresses. There have been numerical studies of residual stress through multiple particle impact simulations, which confirm this view [143-145]. Theoretical evaluation of the residual stress is nevertheless not straightforward. The sign, magnitude and profile of residual stresses in cold-sprayed coatings depend on various factors, such as cold spray process parameters, e.g. as shown for aluminium coating [146]. An example of measured residual stress profiles using neutron diffraction [147] is shown in Fig. 25. 


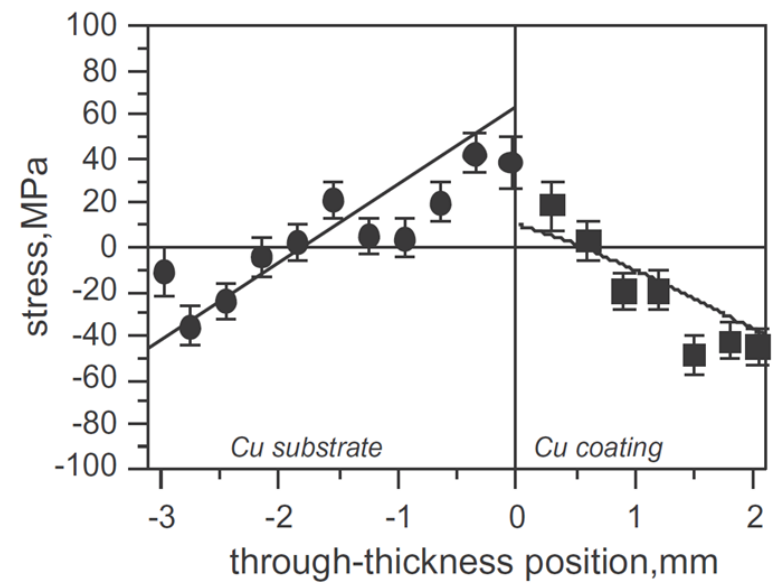

Figure 25. Residual stress measured using neutron scattering for copper coatings cold sprayed on copper substrate [147]. The solid lines correspond to the progressively deposited coating model [148] fitted into the experimental data.

The results were shown to fit to Tsui and Clyne's progressive coating deposition model [148]. According to this model, the coating deposition is considered as progressive formation of a new layer on the top of the previously deposited coating layers. This new layer is formed with a characteristic deposition stress, which is invariably compressive. Nevertheless, after spraying, the substrate and coating system is normally cooled down to room temperature, so that a thermal misfit strain may arise. Thus, the residual stress can be influenced by the heat input, spraying kinematics and the associated thermal history. Based on these factors, in addition to substrate and coating material properties and dimensions, the mean residual stress in the coating can be compressive or tensile $[149,150]$.

\section{Cold spray parameters}

Cold spray parameters may be divided into three groups as follows: (1) process parameters, such as gas conditions, nozzle design and spraying kinematics, (2) powder properties, and (3) substrate properties, as discussed below. Based on these parameters, materials can then be sorted in terms of sprayability, that is, the capability of being successfully deposited by CS. 


\subsection{Process parameters}

There are several process parameters that play a role in CS [98]. A major part of cold spray research has aimed to investigate - often through fluid dynamics considerations - the influence of the process parameters on the deposition efficiency and on the final properties of the deposits. On the other hand, properties of the deposits are known to depend mainly on the particle impact conditions - i.e. particle impact velocity, $v_{\mathrm{p}}$, particle impact temperature, $T_{p}$, and surface temperature of the substrate, or of the already deposited layer, $T_{\text {sub. }}$ Thus, the aim of most investigations has been to work out the relationship between the cold spray process parameters on the one hand and on the other hand these three key parameters, i.e. $v_{\mathrm{p}}, T_{p}$ and

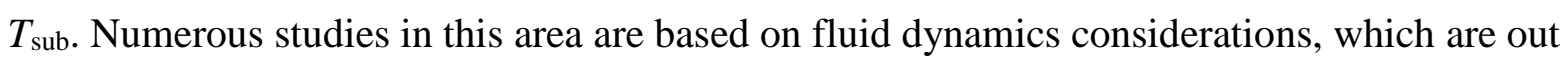
of scope of the present paper. Nevertheless, table 1 offers a qualitative summary of the effect of various process parameters on the relevant impact parameters, including those relating to fluid dynamics.

Table 1. Summary of the effect of process parameters on the impact conditions

\begin{tabular}{|c|c|c|c|c|}
\hline Factor & Parameter & Effect on $v_{p}$ & Effect on $T_{p}$ & Effect on $T_{\text {sub }}$ \\
\hline \multirow{3}{*}{ Gas } & Type ${ }^{(1)}$ & $v_{\mathrm{p}}(\mathrm{He})>v_{\mathrm{p}}\left(\mathrm{N}_{2}\right)$ & $T_{\mathrm{p}}(\mathrm{He})<T_{\mathrm{p}}\left(\mathrm{N}_{2}\right)$ & \multirow{3}{*}{$T_{\mathrm{gas}} \uparrow \Rightarrow T_{\mathrm{sub}} \uparrow$} \\
\hline & $T_{\text {gas }}$ & $T_{\mathrm{gas}} \uparrow \Rightarrow v_{\mathrm{p}} \uparrow$ & $T_{\mathrm{gas}} \uparrow \Rightarrow T_{\mathrm{p}} \uparrow$ & \\
\hline & $p_{\text {gas }}$ & $p_{\mathrm{gas}} \uparrow \Rightarrow v_{\mathrm{p}} \uparrow(2)$ & $p_{\text {gas }} \uparrow \Rightarrow T_{\mathrm{p}} \uparrow \downarrow$ & \\
\hline \multirow{3}{*}{ Nozzle } & Length, $l$ & $l \uparrow \Rightarrow v_{\mathrm{p}} \uparrow$ & $l \uparrow \Rightarrow T_{\mathrm{p}} \downarrow$ & $l \uparrow \Rightarrow T_{\mathrm{sub}} \downarrow$ \\
\hline & Exp. ratio, $r$ & $r \uparrow \Rightarrow v_{\mathrm{p}} \uparrow$ & \multirow[t]{2}{*}{$r \uparrow \Rightarrow T_{\mathrm{p}} \downarrow$} & \multirow[t]{2}{*}{$r \uparrow \Rightarrow T_{\text {sub }} \downarrow$} \\
\hline & Diameter, $d$ & $d \uparrow \Rightarrow v_{\mathrm{p}} \uparrow(3)$ & & \\
\hline Prechamber & Length, $l_{\text {pre }}{ }^{(4)}$ & & $l_{\text {pre }} \uparrow \Rightarrow T_{\mathrm{p}} \uparrow$ & \\
\hline \multirow{4}{*}{ Procedure } & Standoff distance, $s$ & $s \uparrow \Rightarrow v_{\mathrm{p}} \uparrow \downarrow(5)$ & \multirow[t]{3}{*}{$s \uparrow \Rightarrow T_{\mathrm{p}} \downarrow$} & \multirow[t]{2}{*}{$s \uparrow \Rightarrow T_{\text {sub }} \downarrow$} \\
\hline & Spraying angle, $\omega^{(6)}$ & $\omega \uparrow \Rightarrow v_{\mathrm{p}} \downarrow$ & & \\
\hline & Traverse speed, $v_{\text {gun }}$ & & & $v_{\text {gun }} \uparrow \Rightarrow T_{\text {sub }} \downarrow$ \\
\hline & Powder feed-rate, $f$ & $f \uparrow \Rightarrow v_{\mathrm{p}} \downarrow$ & $f \uparrow \Rightarrow T_{\mathrm{p}} \uparrow$ & $f \uparrow \Rightarrow T_{\text {sub }} \uparrow$ \\
\hline
\end{tabular}


${ }^{1}$ Main gas properties are molar weight, specific heat, specific heat ratio and viscosity.

${ }^{2}$ Impact velocities of fine particles may drop at high gas pressures because of bow shock.

${ }^{3}$ Larger nozzle diameters normally result in reduced boundary layer and frictional effects.

${ }^{4}$ This is the distance between the powder injection point and the throat of the nozzle.

${ }^{5}$ Increases initially up to a maximum (normally within a few centimetres) then decreases.

${ }^{6}$ Effect on vertical component of the impact velocity with reference to right-angle.

\subsection{Powder}

Particle size distribution is a main attribute of powders suitable for CS. The particle size has opposing effects on the particle velocity and the critical velocity. As discussed above, the critical velocity generally decreases with increasing particle size. On the other hand, larger particles are more difficult to accelerate and also have a larger heat capacity. In view of these complex influences, there is no unique optimum particle size for CS. As will be discussed later, the optimum particle size depends on various factors, including the spraying conditions, nozzle specifications and the length of prechamber.

Particle morphology also plays a role, as discussed in ref [151]. At low spraying conditions, an irregular, e.g. dendritic powder may lead to lower porosity, while at higher spraying conditions spherical powders result in higher strengths. Moreover, particle size and morphology together determine the free surface area per volume, which is yet another relevant factor for CS. A larger surface area could result in faster oxidation kinetics, and hence in degraded coating quality. In the case of spraying reactive powder mixtures for subsequent heat treatments, e.g. for combustion synthesis of intermetallic compounds, particle size and morphology may additionally influence the diffusive reaction kinetics.

According to Eq. (3), the critical velocity is considered to depend on the particle properties. These properties are often taken to be the same as those of bulk material, both for the estimation of the critical velocity and for numerical simulations of particle impact. While this is a valid assumption for density and heat capacity, the strength and plastic properties of micron-sized particles as used for CS may be substantially different from that of bulk material. For some materials - such as MCrAlYs, which are produced in the powder form the bulk material data may not even exist. Therefore, it may be necessary to obtain 
mechanical strength of the single particles, e.g. through single particle compression tests as described in [41]. In combination with numerical simulation of particle compression, a simple correlation has been worked out between the ultimate tensile strength and the force, $F^{*}$, at a displacement equal to half of the initial particle diameter, $d_{\mathrm{p}}$, as follows:

$$
\sigma_{\mathrm{UTS}} \approx(0.9 \pm 0.1) \frac{F^{*}}{d_{\mathrm{p}}{ }^{2}}
$$

For the case of copper particles, the single-particle compression tests have shown a significant difference between particle and bulk properties.

\subsection{Substrate}

Substrate hardness influences the adhesion between the coating and the substrate. This can be explained in terms of particle deceleration, or the 'impact power', which is the rate of kinetic energy dissipation during impact of single particle. In CS, the impact power is typically around $50 \mathrm{~W}$. For harder substrates, the impact power is higher and heat generation it is restricted to smaller volumes, leading to more pronounced temperature rise and facilitated ASI on the particle side. Likewise, an impacting particle penetrates more deeply into a softer substrate, facilitating ASI on the substrate side, while particle deceleration and the corresponding impact power may be lower. The adhesion strength is influenced by the combination of impact power and the distribution of energy dissipation in particle and substrate. Therefore, hardness of the substrate is an important consideration for the adhesion strength.

Mechanical properties of the substrate influence not only the adhesion strength, but also the intrinsic properties of the coating such as the flattening ratio of the particles [152]. This is because of the effect of substrate hardness on the deformation behaviour of the already deposited layers. For instance, a hard substrate constrains the deformation of the first layer of deposited particles, thus influences the cohesion between the first and subsequent layers. This effect is nevertheless limited only to a few particle layers, i.e. to a few tens of microns. After about $50 \mu \mathrm{m}$, the already deposited material deforms in the same way as a much thicker deposit. 
For very soft substrates such as polymers successful deposition may require using relatively low particle velocities and temperatures, to allow successful deposition without eroding the substrate away. Examples of metallic coatings on polymer substrates are given in [153-157]. Low velocities may also be used for coating deposition of metals on ceramics, to avoid fracture of the generally brittle substrate. Additionally, deposition of metals on ceramics may be facilitated by using an interlayer [158] - or by substrate preheating, as discussed below.

Particle bonding is influenced not only by the particle temperature, but also by the surface temperature of the substrate or the already deposited layers on which the particles impact [159]. Note that the surface temperature is different from the initial substrate temperature. It is influenced by various factors including the initial substrate temperature, spraying conditions, spraying kinematics and the thermal properties and dimensions of the substrate. The effect of substrate preheating on bonding is shown is demonstrated for CS of magnesium [160], aluminium [161], copper [162,163], nickel [164] and steel 316L [165]. The trend and the intensity of this effect depend on the combination of coating-substrate materials and on the surface oxidation of the substrate, which may occur due to excessive preheating time or temperature [166]. For the case of copper sprayed on ceramic (alumina) substrates, increased substrate temperature resulted in significant increase of not only the adhesive strength, but also the overall coating quality [167]. This may be attributed to some extent to partial recovery of the deposit during spraying.

Substrate roughness may also play a role; e.g. it can lead to higher deposition efficiency of the first layer [168]. However, it may not necessarily result in increased bond strength [169]. An example of the effect of various surface preparation methods on CS of an aluminium alloy is given in [170].

\subsection{Sprayability and parameter selection}

Conventionally, the critical velocity has been taken as a measure of sprayability of various materials. This can nevertheless be misleading. As mentioned above, many cold-spray properties depend on not only the critical velocity but also the particle impact conditions. Therefore, sprayability should be more appropriately discussed in view of the velocity ratio, $\eta$, or of the energy parameter $\eta_{E}$. 
Table 2 shows a selection of materials, sorted based on the respective critical velocities, and also sorted based on the calculated velocity ratios for different particle sizes and spraying conditions. The dark grey (green in colour version) background shows sprayability, while the light grey (orange in colour version) background signifies melting and nozzle clogging. It should be noted that not only low-melting point materials, but also nickel and nickel alloys are prone to nozzle clogging at high process gas temperatures, thus practically limiting sprayability. Countermeasures include water cooling as well as using nozzle materials that are resistant to clogging. Moreover, nozzle clogging can be avoided by using helium instead of nitrogen as process gas - which may be commercially justified in special cases - so that the same value of $\eta$ is achieved at lower temperatures.

Table 2. Sprayability of selected materials*

\begin{tabular}{|c|c|c|c|c|c|c|c|c|c|}
\hline \multirow[b]{2}{*}{ Material } & \multirow[b]{2}{*}{$V_{c r}\left(T_{p}=20^{\circ} \mathrm{C}\right)$} & \multicolumn{4}{|c|}{$T_{g}=400^{\circ} \mathrm{C}, p_{g}=30 \mathrm{bar}$} & \multicolumn{4}{|c|}{$T_{g}=800^{\circ} \mathrm{C}, p_{g}=40 \mathrm{bar}$} \\
\hline & & Material & $\eta\left(d_{p}=30 \mu \mathrm{m}\right)$ & Material & $\eta\left(d_{p}=50 \mu \mathrm{m}\right)$ & Material & $\eta\left(d_{p}=30 \mu \mathrm{m}\right)$ & Material & $\eta\left(d_{p}=50 \mu \mathrm{m}\right)$ \\
\hline Zinc & 339 & Zinc & 2.18 & Zinc & 2.15 & Zinc & - & Zinc & - \\
\hline Tantalum & 447 & Aluminium & 1.44 & Aluminium & 1.50 & Mg-AZ91 & - & Mg-AZ91 & - \\
\hline Copper & 451 & Copper & 1.29 & Al-6061 & 1.35 & Al-7075 & - & Al-7075 & - \\
\hline Aluminium & 482 & Al-6061 & 1.28 & Copper & 1.27 & Al-6061 & - & Al-6061 & - \\
\hline CuZn30 & 505 & CuZn30 & 1.17 & Magnesium & 1.23 & Aluminium & - & Magnesium & - \\
\hline Al-6061 & 556 & Al-7075 & 1.16 & Al-7075 & 1.21 & Magnesium & - & Aluminium & - \\
\hline Niobium & 564 & Magnesium & 1.11 & Mg-AZ91 & 1.13 & Copper & 1.92 & Copper & 1.86 \\
\hline Nickel & 574 & Tantalum & 1.04 & CuZn30 & 1.11 & CuZn30 & 1.85 & CuZn30 & 1.73 \\
\hline CuAl9Ni2 & 594 & CuA19Ni2 & 0.99 & Tantalum & 0.96 & CuAl9Ni2 & 1.51 & CuAl9Ni2 & 1.43 \\
\hline Iron & 596 & Mg-AZ91 & 0.99 & CuAl9Ni2 & 0.95 & Nickel & 1.35 & Nickel & 1.25 \\
\hline Molybdenum & 605 & Nickel & 0.97 & Nickel & 0.91 & Tantalum & 1.33 & Iron & 1.24 \\
\hline Magnesium & 607 & Niobium & 0.96 & Iron & 0.91 & ron & 1.32 & Tantalum & 1.22 \\
\hline Steel 409 & 630 & ron & 0.95 & Niobium & 0.91 & Steel 409 & 1.27 & Steel 316L & 1.19 \\
\hline Steel 316L & 655 & Steel 409 & 0.91 & Steel 316L & 0.86 & Niobium & 1.25 & Steel 409 & 1.19 \\
\hline Al-7075 & 658 & Steel 316L & 0.88 & Steel 409 & 0.86 & Steel 316L & 1.24 & Niobium & 1.18 \\
\hline Titanium & 712 & Molybdenum & 0.86 & Titanium & 0.84 & Titanium & 1.17 & Titanium & 1.15 \\
\hline Mg-AZ91 & 726 & Titanium & 0.85 & Molybdenum & 0.81 & Molybdenum & 1.12 & Molybdenum & 1.05 \\
\hline TiAl6V4 & 1013 & $\mid$ TiAl6V4 & 0.60 & TiAl6V4 & 0.59 & $\mid$ TiAl6V4 & 0.83 & TiAl6V4 & 0.82 \\
\hline
\end{tabular}

* In the left column materials are sorted based on the critical velocity (ascending order) whereas in the other columns they are sorted based on the respective $\eta$ values (descending order) as calculated for nitrogen and nozzle D24, but for different particle size and spraying conditions (courtesy of Kinetic Spray Solutions GmbH, Buchholz, Germany). 
It is interesting to note that the order of materials changes from one column to another in the table. For instance, based on the critical velocity, tantalum appears as the second 'easiest' material for CS, after zinc. With respect to the velocity ratio, however, it is not sprayable at 30 bar and $400{ }^{\circ} \mathrm{C}$. This is simply because of high density of tantalum, making it difficult to accelerate. The opposite is true for magnesium. It is also interesting to note that the order of materials changes in every case, by changing the spraying condition or the particle size. This means that there is no unique set of optimum particle size, and that a suitable particle size must be selected with respect to the intended spraying conditions. In this table, copper is the only material that remains sprayable under all conditions considered.

\section{Materials and applications}

Cold spraying can be used for coating, repair and additive manufacturing (AM). CS deposition of almost all metallic materials and metal-ceramic composites to any thickness above $50 \mu \mathrm{m}$ is conceivable. For a review of successfully cold-sprayed and studied material systems and applications see e.g. [20, 171-174]. Figure 26 shows a few examples of coldsprayed coatings, as investigated by the authors and co-workers at Helmut Schmidt University.

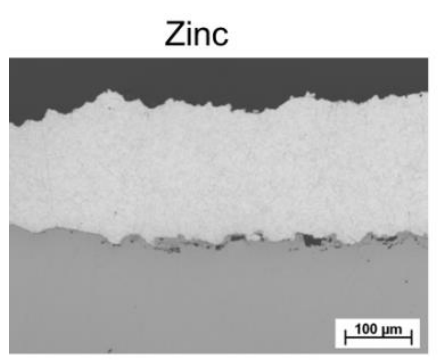

Tantalum

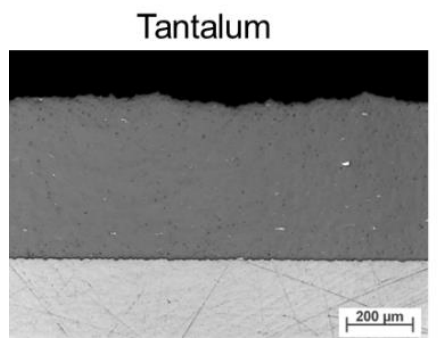

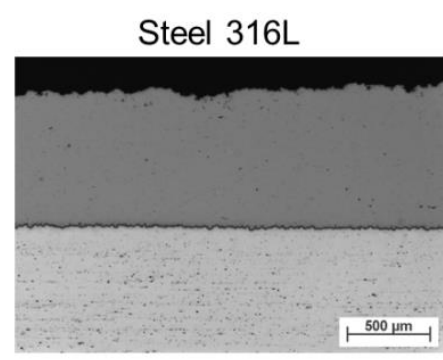

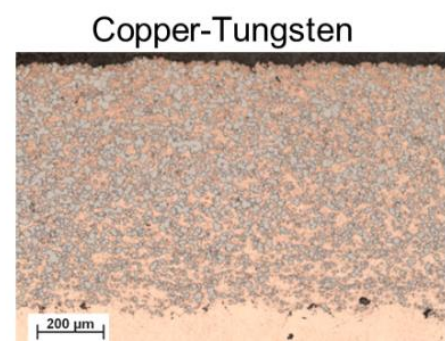

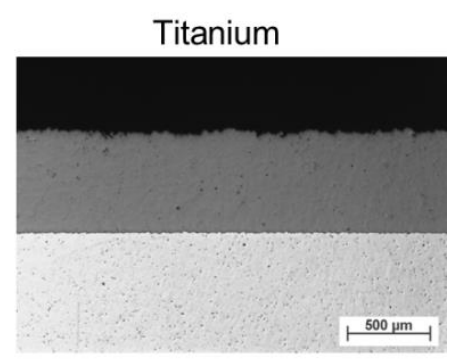

Aluminium-Alumina

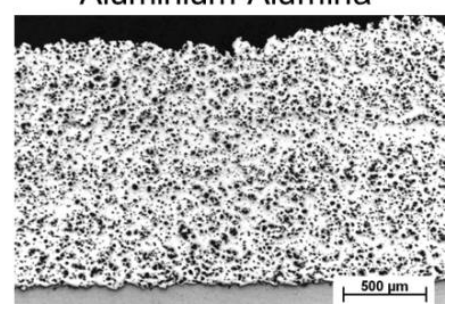

Figure 26. Examples of cold-sprayed coatings [16, 27, 45, 175, 176]. 
Table 3 gives a summary of materials and applications in CS. The list is non-exhaustive, partly because of undisclosed work outside academia. The applications can be categorised based on the intended purpose, as follows: (i) to obtain high purity deposits, (ii) to obtain superior properties through well-bonded interfaces and (iii) to ensure low heat input to the substrate. High purity and well-bonded interfaces result in high electrical and thermal conductivity, as well as in high mechanical strength and high corrosion/oxidation resistance. High chemical purity and homogeneity of the cold-sprayed deposits make them particularly suitable for applications in electronics, chemical and biomedical industries. Besides offering unique deposit properties, CS may also be a suitable option for applications where the substrate is sensitive to thermal shock - e.g. in the case of coating metals on glass or ceramics, or repair of heat-sensitive components. It has also been considered as a method to improve fatigue strength of the substrate [177].

As discussed before, properties of cold-sprayed deposits may be affected by defects and nonbonded interfaces. This problem can nevertheless be minimised by using relatively high velocity ratios - typically higher than 1.5 . Moreover, post spraying heat treatments may be used to increase the extent of bonded areas and to spherodise the remaining discontinuities. In some cases - e.g. in the production of Ni-based superalloy turbine blades - post heat treatments may not need extra efforts, as they may already be an integral part of the production procedure. 
Table 3. An overview of current materials and applications in cold spraying

\begin{tabular}{|c|c|c|c|}
\hline Material & Application & Sector & Merits \\
\hline $\mathrm{Cu}, \mathrm{Ag}$ & $\begin{array}{l}\text { Conductive layers; } \\
\text { high power electronics } \\
\text { Sensors } \\
\text { Heat transfer layers } \\
\text { Corrosion protection } \\
\end{array}$ & $\begin{array}{l}\text { Electronics } \\
\text { Automotive } \\
\text { Energy } \\
\text { Nuclear } \\
\quad \text { industries } \\
\end{array}$ & $\begin{array}{l}\text { High chemical homogeneity, } \\
\text { no oxidation } \\
\text { Similar conductivity as bulk material }\end{array}$ \\
\hline $\begin{array}{l}\mathrm{Al}, \mathrm{Mg} \\
\text { alloys }\end{array}$ & Repair & Aerospace & $\begin{array}{l}\text { Low amounts of interface defects } \\
\text { Similar strength as bulk material }\end{array}$ \\
\hline $\begin{array}{l}\mathrm{Al}, \mathrm{Ti} \\
\text { alloys, } \\
\mathrm{Cu}, \text { Steels }\end{array}$ & $\begin{array}{l}\text { Additive manufacturing } \\
\text { Manufacturing of injection / } \\
\text { die casting moulds }\end{array}$ & $\begin{array}{l}\text { Aerospace } \\
\text { Tooling } \\
\text { Polymer } \\
\text { industry }\end{array}$ & $\begin{array}{l}\text { Low amounts of interface defects } \\
\text { Similar mechanical/fatigue strength } \\
\text { as bulk material } \\
\text { High deposition rates } \\
\text { Complex combination of different } \\
\text { materials in one component }\end{array}$ \\
\hline $\begin{array}{l}\mathrm{Ta}, \mathrm{Nb}, \mathrm{Cu} \\
\text { alloys }\end{array}$ & $\begin{array}{l}\text { Additive manufacturing } \\
\text { Sputter targets }\end{array}$ & $\begin{array}{l}\text { Electronics } \\
\text { Machinery }\end{array}$ & $\begin{array}{l}\text { High purity, high chemical } \\
\text { homogeneity, no oxidation }\end{array}$ \\
\hline $\begin{array}{l}\mathrm{Ni}, \mathrm{Ta}, \\
\text { High-Cr } \\
\text { steels }\end{array}$ & $\begin{array}{l}\text { Cathodic corrosion } \\
\text { protection }\end{array}$ & $\begin{array}{l}\text { Offshore } \\
\text { Chemical Ind. }\end{array}$ & $\begin{array}{l}\text { Low amounts of interface defects } \\
\text { High chemical homogeneity, } \\
\text { no oxidation }\end{array}$ \\
\hline $\begin{array}{l}\mathrm{Zn}, \mathrm{Al} \\
\text { alloys }\end{array}$ & Anodic corrosion protection & $\begin{array}{l}\text { Offshore } \\
\text { Chemical } \\
\text { Machinery }\end{array}$ & $\begin{array}{l}\text { High chemical homogeneity, } \\
\text { no oxidation } \\
\text { Dense coatings }\end{array}$ \\
\hline $\mathrm{Cu}$ alloys & $\begin{array}{l}\text { Tribological performance } \\
\text { Cavitation resistance }\end{array}$ & $\begin{array}{l}\text { Maritime } \\
\text { technologies } \\
\text { Machinery }\end{array}$ & $\begin{array}{l}\text { Low amounts of interface defects } \\
\text { Similar mechanical strength as bulk } \\
\text { material }\end{array}$ \\
\hline $\begin{array}{l}\text { Steels } \\
\text { austenitic } \\
\text { ferritic }\end{array}$ & $\begin{array}{l}\text { Repair } \\
\text { Magnetic properties } \\
\quad \text { (induction heating) }\end{array}$ & $\begin{array}{l}\text { Energy } \\
\text { Machinery } \\
\text { Consumer goods }\end{array}$ & $\begin{array}{l}\text { Low amounts of interface defects } \\
\text { Similar strength as bulk material } \\
\text { Chemical homogeneity, } \\
\text { no oxidation }\end{array}$ \\
\hline Ni alloys & $\begin{array}{l}\text { Hot gas corrosion protection } \\
\text { Repair }\end{array}$ & $\begin{array}{l}\text { Energy } \\
\text { Aerospace }\end{array}$ & $\begin{array}{l}\text { Low amounts of interface defects } \\
\text { Chemical homogeneity, } \\
\text { no oxidation }\end{array}$ \\
\hline Ti alloys & Biocompatible parts & Medicine & $\begin{array}{l}\text { Chemical homogeneity, purity, } \\
\text { no oxidation }\end{array}$ \\
\hline
\end{tabular}

Another technically interesting characteristic of the CS process is the relatively small sprayline width of 6-8 mm, which makes it suitable for AM applications. For applications in electronics, however, the line width may need to be further reduced. This can be achieved via 
masking techniques. In repair or AM applications, CS offers deposition rates that are by about an order of magnitude higher than those in selective laser deposition techniques. For these applications, elaborate robotics are normally required, mainly to ensure orthogonal spraying ( $\eta$ decreases with deviation from right angle) and constant standoff distance. In practice, material deposition is combined with machining, and the final part is often heat treated to improve ductility. The concept of using CS for AM - e.g. to produce titanium parts - is almost as old as the process itself [178]. It is nowadays commercially implemented; an example of this is shown in Fig. 27.

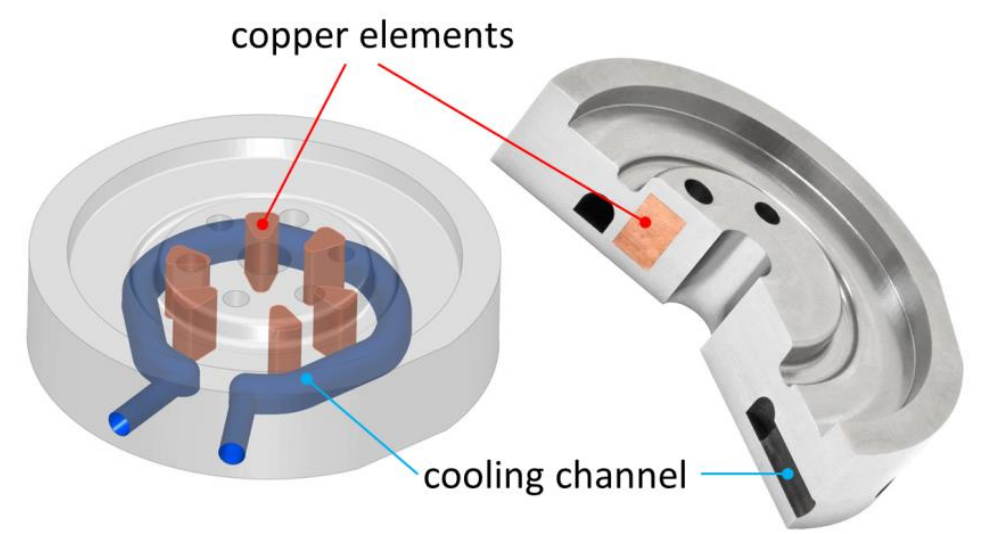

Figure 27. Example of an additively manufactured part with copper and tool steel with cooling channel - drawing (left) and real part (right) - using MPA technology from Hermle Maschinenbau GmbH, Ottobrunn, Germany.

\subsection{Metallic materials}

There have been many studies on cold spraying of metallic materials. The literature on this topic alone already includes a few review articles. Table 4 gives only a selection of the published work on CS of different metallic materials. The table excludes the work on metallic glasses, which are discussed separately below. 
Table 4. A selection of published work on cold spraying of metallic materials

\begin{tabular}{|c|c|c|}
\hline Material & Reference & Remark \\
\hline $\mathrm{Ag}$ & {$[179]$} & Electrical conductivity \\
\hline Al alloys & $\begin{array}{l}\text { A most widely studied material system; } \\
\text { nearly a hundred published papers }\end{array}$ & $\begin{array}{l}\text { Aerospace } \\
\text { Automotive }\end{array}$ \\
\hline Bronze & [180-182] & Cavitation resistance \\
\hline $\mathrm{Cu}$ & {$[24,70,107,183-185]$} & $\begin{array}{l}\text { Early studies, reference material } \\
\text { Nanocrystals } \\
\text { Electrodes }\end{array}$ \\
\hline $\mathrm{Cu}-\mathrm{Ni}-\mathrm{Fe}$ & {$[186]$} & Aluminium production \\
\hline MCrAlY & {$[27,135,187]$} & $\begin{array}{l}\text { Phase transformation } \\
\text { Turbine blades }\end{array}$ \\
\hline Mg alloys & {$[188]$} & Review \\
\hline $\mathrm{Ni}$ & {$[189,190]$} & $\begin{array}{l}\text { Hydrogen generation } \\
\text { Nanocrystals }\end{array}$ \\
\hline $\mathrm{Ni}-\mathrm{Cr}$ & [191-194] & High-temperature applications \\
\hline Ni-based superalloys & {$[195,196]$} & High-temperature applications \\
\hline NiTi & {$[197,198]$} & $\begin{array}{l}\text { Shape memory } \\
\text { Nanocrystals }\end{array}$ \\
\hline Steel 316L, 304L & {$[134,199-201]$} & $\begin{array}{l}\text { Heat treatment } \\
\text { Phase transformation }\end{array}$ \\
\hline Stellite & [202-204] & Wear resistance \\
\hline $\mathrm{Ta}$ & {$[197,198]$} & $\begin{array}{l}\text { Oxygen evolution reaction } \\
\text { Corrosion protection }\end{array}$ \\
\hline $\mathrm{Ti}$ & {$[205,206]$} & Review \\
\hline $\mathrm{Zn}, \mathrm{Zn}$ alloys & {$[176,207]$} & $\begin{array}{l}\text { Printing rolls } \\
\text { Corrosion protection }\end{array}$ \\
\hline
\end{tabular}

CS is a particularly attractive method for the deposition of metastable materials such as metallic glasses, without dimensional restriction. In this respect, CS may be considered as the only practical method through which bulk metallic glasses of any size may be produced. With the availability of experimental gas-atomized amorphous feedstock powder in sufficient quantities, first reports on CS of metallic glass coatings were published about a decade ago $[16,84-86,97]$. By using helium as process gas, optimised process conditions, and in some cases powder preheating, dense coating could be produced. Figure 28 shows an example of a 
cold-sprayed Zr-based metallic glass. The obtained coatings exhibited tribological and corrosive properties similar to that of cast BMG [208-210]. More recent studies demonstrated that amorphous coatings of Fe-based BMGs could be deposited by using nitrogen as process gas $[87,88,96,211]$.

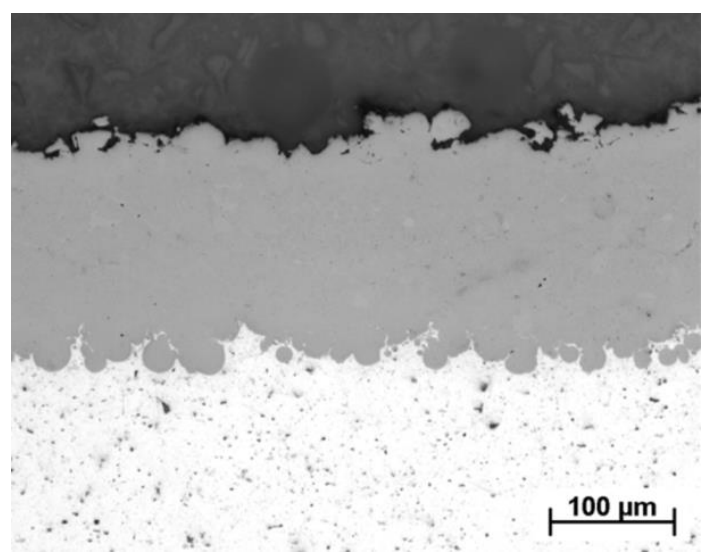

Figure 28. Optical micrograph of the cross section of a $\mathrm{Zr}_{55} \mathrm{Al}_{10} \mathrm{Ni}_{5} \mathrm{Cu}_{30}$ (at. \%) bulk metallic glass coating on an AlMg3 substrate, cold sprayed with helium at 30 bar and $600^{\circ} \mathrm{C} \mathrm{[16].}$

\subsection{Ceramics and composites}

Generally, ceramics can be sprayed successfully only through vacuum cold spraying, i.e. aerosol deposition (AD) [31]. High pressure cold spraying of monolithic ceramic powder usually results in fracture and fragments embedded in the surface of metallic substrates. There are nevertheless a few examples where open-air cold spray has been used to deposit ceramics. Examples include CS of hydroxyapatite (HA) for biomedical applications - pure HA [212, 213], HA mixed with titanium [214] or doped with silver [215] - and titania as photoelectrodes [216-220]. In most cases, the thickness of the deposited material is limited to a monolayer of particles. Also, the success in cold spray deposition of ceramics appears to depend strongly on the structure of particles, which can be agglomerates of nanoparticles (see section 3.2.6). The work on CS of ceramics is in its infancy.

In contrast, there are numerous examples of CS of composite materials. In most cases, there is a metallic component that is to provide deformability and binding between the harder (often ceramic) particulates. Almost any combination of metals and ceramics is conceivable; hence many are explored, including binary $\mathrm{Cu}-\mathrm{W}[221,222]$ and ternary $\mathrm{Cu}-\mathrm{CNT}-\mathrm{SiC}$ 
nanocomposites [223]. Composite coatings can be made by spraying of powder mixtures [224], coated particles [225], ball-milled mixtures [226] or sintered agglomerates. There are some 30 published journal papers on cemented carbides alone; among them just to name a few are those on WC-Ni [227] and WC-Co [228-231]. Moreover, many articles report on CS of Al-based composites; examples of recent studies include CS of Al5056-Inconel718 [232], $\mathrm{Al}-\mathrm{Al} 2 \mathrm{O} 3$ [233] and Al5056-SiC [234].

Polymers can also be used as the deformable component [235], though this is not common. The second phase is sometimes a temperature sensitive material such as CNT [223], nanodiamond [236, 237], metallic glass [238], or quasicrystal [239, 240], for which cold spray offers a unique merit of not inducing thermal degradation. In some cases a cold sprayed composite is produced as a precursor for subsequent reactive synthesis, e.g. to form intermetallic compounds [241-243] or to make use of the generated heat as in thermite reaction [244]. There are yet many combinations of materials for various purposes to be explored.

\section{Summary and outlook}

Cold spraying may be regarded as an established method for coating and additive manufacturing. In terms of industrial applications, it offers unique merits such as low oxidation and preservation of the initial microstructure, not achievable by any other powder deposition method. It can also be used as an experimental method to study materials under ultra-high strain-rate deformation or to explore shock-induced transformation. There has been much interest in research on cold spraying, and hence, much knowledge has been produced on various aspects of this process within the past two decades. Mechanism of deposition, at least for metallic materials, is well explored and extensively discussed. The process has thus been optimised for various materials and applications in industry. Nevertheless, there is much room for further studies in cold spraying of materials systems and substrate/coating combinations that have not been explored so far. Also, new criteria may be needed to understand and optimise deposition of materials with special deformation behaviour such as intermetallics, metallic glasses, ceramics and composites. 


\section{Acknowledgements}

The authors thankfully acknowledge the German Research Foundation (DFG), the German Foundation of Industrial Research Associations (AiF), the German Federal Ministry of Economics and Technology (BMWi), and Volkswagen Foundation for financially supporting the research on cold spray at Helmut Schmidt University Hamburg.

\section{References}

[1] Alkhimov AP, Kosarev VF, Nesterovich NI, Papyrin AN. Method of applying coatings (SU 1618778); prio. June 6th, 1986.

[2] Alkhimov AP, Kosarev VF, Papyrin AN. A method of cold gas-dynamic deposition. Soviet Physics-Doklady 1990;35:1047-1049.

[3] Alkhimov AP, Papyrin AN, Kosarev VF, Nesterovich NI, Shushpanov MM. Gas-dynamic spraying method for applying a coating (US 5302414): Patent; 1994.

[4] Irissou E, Legoux J, Ryabinin AN, Jodoin B, Moreau C. Review on cold spray process and technology: Part I - Intellectual property. Journal of Thermal Spray Technology 2008; 17:495-516.

[5] McCune RC, Papyrin AN, Hall JN, Riggs WL, Zajchowski PH. An exploration of the cold gas-dynamic spray method for several material systems, in: Berndt CC, Sampath S (Eds.). Advances in Thermal Spray Science and Technology. Materials Park: ASM International; 1995. p. 1-5.

[6] Tokarev AO. Structure of aluminum powder coatings prepared by cold gas dynamic spraying. Metal Science and Heat Treatment 1996;38:136-139.

[7] Alkhimov AP, Klinkov SV, Kosarev VF, Papyrin AN. Gas-dynamic spraying study of a plane supersonic two-phase jet. Journal of Applied Mechanics and Technical Physics 1997;38:324-330. 
[8] Alkhimov AP, Kosarev VF, Papyrin AN. Gas-dynamic spraying. An experimental study of the spraying process. Journal of Applied Mechanics and Technical Physics 1998;39:318-323.

[9] Papyrin A. Cold spray technology. Advanced Materials and Processes 2001;159:49-51.

[10] Dykhuizen RC, Smith MF. Gas dynamic principles of cold spray. Journal of Thermal Spray Technology 1998;7:205-212.

[11] Gilmore DL, Dykhuizen RC, Neiser RA, Smith MF, Roemer TJ. Particle velocity and deposition efficiency in the cold spray process. Journal of Thermal Spray Technology 1999;8:576-582.

[12] van Steenkiste TH, Smith JR, Teets RE, Moleski JJ, Gorkiewicz DW, Tison RP, Marantz DR, Kowalsky KA, Riggs WL, Zajchowski PH, Pilsner B, McCune RC, Barnett KJ. Kinetic spray coatings. Surface and Coatings Technology 1999;111:62-71.

[13] Kreye H, Stoltenhoff T. Cold spraying - a study of process and coating characteristics, in: Proceedings of the International Thermal Spray Conference; 2000.

[14] Xiong T, Wu J, Jin HZ, Li M, Liu X, Li TF. Introduction to a new technology - cold gas dynamic spray. Corrosion Science and Protection Technology 2001;13:267-269.

[15] Kosarev VF, Klinkov SV, Alkhimov AP, Papyrin AN. On some aspects of gas dynamics of the cold spray process. Journal of Thermal Spray Technology 2003;12:265281.

[16] Gärtner F, Schmidt T, Stoltenhoff T, Kreye H. Recent developments and potential applications of cold spraying. Advanced Engineering Materials 2006;8:611-618.

[17] Champagne VK. The Cold Spray Materials Deposition Process: Fundamentals and Applications. Elsevier; 2007.

[18] Papyrin A, Kosarev V, Klinkov S, Alkhimov A, Fomin VM. Cold Spray Technology. Elsevier; 2006. 
[19] Wang Q, Zhang M. Review on recent research and development of cold spray technologies. Key Engineering Materials 2013;533:1-52.

[20] Moridi A, Hassani-Gangaraj SM, Guagliano M, Dao M. Cold spray coating: Review of material systems and future perspectives. Surface Engineering 2014;30:369-395.

[21] Grigoriev S, Okunkova A, Sova A, Bertrand P, Smurov I. Cold spraying: From process fundamentals towards advanced applications. Surface and Coatings Technology 2015;268:77-84.

[22] Villafuerte J. Modern Cold Spray: Materials, Process, and Applications; 2015.

[23] Kay CM, Karthikeyan J (Eds.). High Pressure Cold Spray: Principles and Applications: ASM International; 2016.

[24] Stoltenhoff T, Borchers C, Gärtner F, Kreye H. Microstructures and key properties of cold-sprayed and thermally sprayed copper coatings. Surface and Coatings Technology 2006;200:4947-4960.

[25] Smith MF. Comparing cold spray with thermal spray coating technologies, in: The Cold Spray Materials Deposition Process: Fundamentals and Applications; 2007. p. 4361.

[26] Watanabe M, Kumai S. High-speed deformation and collision behavior of pure aluminum plates in magnetic pulse welding. Materials Transactions 2009;50:2035-2042.

[27] Stoltenhoff T, Kreye H, Richter HJ. An analysis of the cold spray process and its coatings. Journal of Thermal Spray Technology 2002;11:542-550.

[28] Lee K, Lee M, Yu J, Kim H. Effect of powder preheating temperature on the properties of titanium coating layers manufactured by kinetic spraying. Materials Transactions 2014;55:622-628.

[29] Koivuluoto H, Coleman A, Murray K, Kearns M, Vuoristo P. High pressure cold sprayed (HPCS) and low pressure cold sprayed (LPCS) coatings prepared from $\mathrm{OFHC} \mathrm{Cu}$ feedstock: Overview from powder characteristics to coating properties. Journal of Thermal Spray Technology 2012;21:1065-1075. 
[30] Akedo J. Room temperature impact consolidation (RTIC) of fine ceramic powder by aerosol deposition method and applications to microdevices. Journal of Thermal Spray Technology 2008;17:181-198.

[31] Hanft D, Exner J, Schubert M, Stöcker T, Fuierer P, Moos R. An overview of the aerosol deposition method: process fundamentals and new trends in materials applications. Journal of Ceramic Science and Technology 2015;6:147-182.

[32] Bray M, Cockburn A, O’Neill W. The laser-assisted cold spray process and deposit characterisation. Surface and Coatings Technology 2009;203:2851-2857.

[33] Olakanmi EO, Doyoyo M. Laser-assisted cold-sprayed corrosion- and wear-resistant coatings: A review. Journal of Thermal Spray Technology 2014;23:765-785.

[34] Christoulis DK, Guetta S, Irissou E, Guipont V, Berger MH, Jeandin M, Legoux J, Moreau C, Costil S, Boustie M, Ichikawa Y, Ogawa K. Cold-spraying coupled to nanopulsed Nd-YaG laser surface pre-treatment. Journal of Thermal Spray Technology 2010;19:1062-1073.

[35] Kulmala M, Vuoristo P. Influence of process conditions in laser-assisted low-pressure cold spraying. Surface and Coatings Technology 2008;202:4503-4508.

[36] Jen T, Pan L, Li L, Chen Q, Cui W. The acceleration of charged nano-particles in gas stream of supersonic De-Lavel-type nozzle coupled with static electric field. Applied Thermal Engineering 2007;27:2877-2885.

[37] Takana H, Ogawa K, Shoji T, Nishiyama H. Computational simulation of cold spray process assisted by electrostatic force. Powder Technology 2008;185:116-123.

[38] Johnson GR, Cook WH. A constitutive model and data for metals subjected to large strains, high strain rates and high temperatures, in: Proceedings of the 7th International Symposium on Ballistics, The Netherlands; 1983. p. 541-547.

[39] Rahmati S, Ghaei A. The use of particle/substrate material models in simulation of cold-gas dynamic-spray process. Journal of Thermal Spray Technology 2014;23:530-540. 
[40] Assadi H, Gärtner F, Stoltenhoff T, Kreye H. Bonding mechanism in cold gas spraying. Acta Materialia 2003;51:4379-4394.

[41] Assadi H, Irkhin I, Gutzmann H, Gärtner F, Schulze M, Villa Vidaller M, Klassen T. Determination of plastic constitutive properties of microparticles through single particle compression. Advanced Powder Technology 2015;26:1544-1554.

[42] Fleck NA, Hutchinson JW. A phenomenological theory for strain gradient effects in plasticity. Journal of the Mechanics and Physics of Solids 1993;41:1825-1857.

[43] Fleck NA, Muller GM, Ashby MF, Hutchinson JW. Strain gradient plasticity: theory and experiment. Acta Metallurgica et Materialia 1994;42:475-487.

[44] Sakai T, Jonas JJ. Dynamic recrystallization: mechanical and microstructural considerations. Acta Metallurgica 1984;32:189-209.

[45] Schmidt T, Gärtner F, Assadi H, Kreye H. Development of a generalized parameter window for cold spray deposition. Acta Materialia 2006;54:729-742.

[46] Wright TW. The physics and mathematics of adiabatic shear bands: Cambridge University Press; 2002.

[47] Schoenfeld SE, Wright TW. A failure criterion based on material instability. International Journal of Solids and Structures 2003;40:3021-3037.

[48] Li W, Zhang DD, Huang CJ, Yin S, Yu M, Wang FF, Liao H. Modelling of impact behaviour of cold spray particles: Review. Surface Engineering 2014;30:299-308.

[49] Dykhuizen RC, Smith MF, Gilmore DL, Neiser RA, Jiang X, Sampath S. Impact of high velocity cold spray particles. Journal of Thermal Spray Technology 1999; Volume $8: 559-564$.

[50] Hertel Jr ES, Bell RL, Elrick MG, Farnsworth AV, Kerley GI, McGlaun JM, Petney SV, Silling SA, Taylor PA, Yarrington L. CTH: A software family for multi-dimensional shock physics analysis, in: Shock Waves@ Marseille I: Springer; 1995. p. 377-382. 
[51] Assadi H, Gärtner F, Stoltenhoff T, Kreye H. Application of analytical methods for understanding and optimization of cold spray process, in: Heinrich P (Ed.). High-Velocity Oxy-Fuel Flame Spraying (HVOF) Colloquium; 2003. p. 49-59.

[52] Grujicic M, Saylor JR, Beasley DE, DeRosset WS, Helfritch D. Computational analysis of the interfacial bonding between feed-powder particles and the substrate in the cold-gas dynamic-spray process. Applied Surface Science 2003;219:211-227.

[53] Li W, Liao H, Li C, Li G, Coddet C, Wang X. On high velocity impact of micro-sized metallic particles in cold spraying. Applied Surface Science 2006;253:2852-2862.

[54] Bae G, Xiong Y, Kumar S, Kang K, Lee C. General aspects of interface bonding in kinetic sprayed coatings. Acta Materialia 2008;56:4858-4868.

[55] Yin S, Wang X, Li W, Xu B. Numerical investigation on effects of interactions between particles on coating formation in cold spraying. Journal of Thermal Spray Technology 2009;18:686-693.

[56] Yin S, Wang X, Li W, Liao H, Jie H. Deformation behavior of the oxide film on the surface of cold sprayed powder particle. Applied Surface Science 2012;259:294-300.

[57] Yin S, Wang X, Suo X, Liao H, Guo Z, Li W, Coddet C. Deposition behavior of thermally softened copper particles in cold spraying. Acta Materialia 2013;61:5105-5118.

[58] Meng F, Aydin H, Yue S, Song J. The effects of contact conditions on the onset of shear instability in cold-spray. Journal of Thermal Spray Technology 2015;24:711-719.

[59] Assadi H, Gärtner F, Klassen T. Modeling and simulation of cold spray, in: Kay CM, Karthikeyan J (Eds.). High Pressure Cold Spray: Principles and Applications: ASM International; 2016.

[60] Manap A, Nooririnah O, Misran H, Okabe T, Ogawa K. Experimental and SPH study of cold spray impact between similar and dissimilar metals. Surface Engineering 2014;30:335-341. 
[61] Li W, Yin S, Wang X. Numerical investigations of the effect of oblique impact on particle deformation in cold spraying by the SPH method. Applied Surface Science 2010;256:3725-3734.

[62] Ogawa H. Atomistic simulation of the aerosol deposition method with zirconia nanoparticles. Materials Transactions 2006;47:1945-1948.

[63] Daneshian B, Assadi H. Impact behavior of intrinsically brittle nanoparticles: A molecular dynamics perspective. Journal of Thermal Spray Technology 2014;23:541-550.

[64] Papyrin AN, Kosarev VF, Klinkov SV, Alkhimov AP. On the interaction of high speed particles with a substrate under the cold spraying, in: Proceedings of the International Thermal Spray Conference; 2002.

[65] Kreye H, Hammerschmidt M, Woidneck C. Discussion on the fusion characteristics during the process of explosion welding. Schweissen und Schneiden/Welding and Cutting 1985;37:297-302.

[66] Berlin A, Nguyen TC, Worswick MJ, Zhou Y. Metallurgical analysis of magnetic pulse welds of AZ31 magnesium alloy. Science and Technology of Welding and Joining 2011;16:728-734.

[67] Barradas S, Guipont V, Molins R, Jeandin M, Arrigoni M, Boustie M, Bolis C, Berthe L, Ducos M. Laser shock flier impact simulation of particle-substrate interactions in cold spray. Journal of Thermal Spray Technology 2007;16:548-556.

[68] Schmidt T. Kaltgasspritzen - Eine Analyse des Materialverhaltens beim Partikelaufprall und die daraus abgeleitete Prozessoptimierung: Thesis, Helmut-SchmidtUniversität, Hamburg: Published by Shaker Verlag, Aachen; 2007.

[69] Villa Vidaller M, List A, Gärtner F, Klassen T, Dosta S, Guilemany JM. Single impact bonding of cold sprayed Ti-6Al-4V powders on different substrates. Journal of Thermal Spray Technology 2015;24:644-658. 
[70] Schmidt T, Assadi H, Gärtner F, Richter H, Stoltenhoff T, Kreye H, Klassen T. From particle acceleration to impact and bonding in cold spraying. Journal of Thermal Spray Technology 2009;18:794-808.

[71] Grujicic M, Zhao CL, DeRosset WS, Helfritch D. Adiabatic shear instability based mechanism for particles/substrate bonding in the cold-gas dynamic-spray process. Materials and Design 2004;25:681-688.

[72] Li W, Zhang C, Guo X, Li C, Liao H, Coddet C. Study on impact fusion at particle interfaces and its effect on coating microstructure in cold spraying. Applied Surface Science 2007;254:517-526.

[73] Bae G, Kumar S, Yoon S, Kang K, Na H, Kim H, Lee C. Bonding features and associated mechanisms in kinetic sprayed titanium coatings. Acta Materialia 2009;57:5654-5666.

[74] Li W, Li C, Yang G. Effect of impact-induced melting on interface microstructure and bonding of cold-sprayed zinc coating. Applied Surface Science 2010;257:1516-1523.

[75] King PC, Bae G, Zahiri SH, Jahedi M, Lee C. An experimental and finite element study of cold spray copper impact onto two aluminum substrates. Journal of Thermal Spray Technology 2010;19:620-634.

[76] Hussain T, McCartney DG, Shipway PH, Zhang D. Bonding mechanisms in cold spraying: The contributions of metallurgical and mechanical components. Journal of Thermal Spray Technology 2009;18:364-379.

[77] Wu J, Fang H, Yoon S, Kim H, Lee C. The rebound phenomenon in kinetic spraying deposition. Scripta Materialia 2006;54:665-669.

[78] Wang K, Kong L, Tao Y, Li T, Xiong T. Numerical simulation of minimal average bonding strength to suppress rebounding in cold spraying $\mathrm{Cu} / \mathrm{Cu}$ : A preliminary study. Journal of Thermal Spray Technology 2014;24:75-85. 
[79] Ji Y, Bae G, Kang K, Lee C. Influence of the interface temperature and strain gradients on the impact energy model of a soft particle on a hard substrate during kinetic spraying. Metals and Materials International 2011;17:335-340.

[80] Song M, Araki H, Kuroda S, Sakaki K. Reaction layer at the interface between aluminium particles and a glass substrate formed by cold spray. Journal of Physics D: Applied Physics 2013;46.

[81] King PC, Zahiri SH, Jahedi M. Focused ion beam micro-dissection of cold-sprayed particles. Acta Materialia 2008;56:5617-5626.

[82] Drehmann R, Grund T, Lampke T, Wielage B, Manygoats K, Schucknecht T, Rafaja D. Interface characterization and bonding mechanisms of cold gas-sprayed $\mathrm{Al}$ coatings on ceramic substrates. Journal of Thermal Spray Technology 2014;24:92-99.

[83] Greer AL, Cheng YQ, Ma E. Shear bands in metallic glasses. Materials Science and Engineering: R: Reports 2013;74:71-132.

[84] Yoon S, Kim H, Lee C. Deposition behavior of bulk amorphous NiTiZrSiSn according to the kinetic and thermal energy levels in the kinetic spraying process. Surface and Coatings Technology 2006;200:6022-6029.

[85] Yoon S, Lee C, Choi H, Jo H. Kinetic spraying deposition behavior of bulk amorphous NiTiZrSiSn feedstock. Materials Science and Engineering A 2006;415:45-52.

[86] Choi H, Yoon S, Kim G, Jo H, Lee C. Phase evolutions of bulk amorphous NiTiZrSiSn feedstock during thermal and kinetic spraying processes. Scripta Materialia 2005;53:125-130.

[87] Concustell A, Henao J, Dosta S, Cinca N, Cano IG, Guilemany JM. On the formation of metallic glass coatings by means of Cold Gas Spray technology. Journal of Alloys and Compounds 2015;651:764-772.

[88] Henao J, Concustell A, Cano IG, Cinca N, Dosta S, Guilemany JM. Influence of cold gas spray process conditions on the microstructure of Fe-based amorphous coatings. Journal of Alloys and Compounds 2015;622:995-999. 
[89] Yoon S, Bae G, Xiong Y, Kumar S, Kang K, Kim J, Lee C. Strain-enhanced nanocrystallization of a CuNiTiZr bulk metallic glass coating by a kinetic spraying process. Acta Materialia 2009;57:6191-6199.

[90] Brinkmann K, Teichler H. Flow state in molecular-dynamics-simulated deformed amorphous Ni0.5Zr0.5. Physical Review B 2002;66:1842051-1842059.

[91] Johnson WL, Demetriou MD, Harmon JS, Lind ML, Samwer K. Rheology and ultrasonic properties of metallic glassforming liquids: A potential energy landscape perspective. MRS Bulletin 2007;32:644-650.

[92] Yoon S, Xiong Y, Kang K, Bae G, Lee C. Phase separation in kinetic sprayed bulk metallic glasses. Journal of Physics D: Applied Physics 2009;42.

[93] Yoon S, Xiong Y, Kim H, Lee C. Dependence of initial powder temperature on impact behaviour of bulk metallic glass in a kinetic spray process. Journal of Physics D: Applied Physics 2009;42.

[94] Demetriou MD, Johnson WL. Shear flow characteristics and crystallization kinetics during steady non-isothermal flow of Vitreloy-1. Acta Materialia 2004;52:3403-3412.

[95] Lohwongwatana B, Schroers J, Johnson WL. Strain rate induced crystallization in bulk metallic glass-forming liquid. Physical Review Letters 2006;96.

[96] List A, Gärtner F, Mori T, Schulze M, Assadi H, Kuroda S, Klassen T. Cold spraying of amorphous Cu50Zr50 alloys. Journal of Thermal Spray Technology 2014;24:108-118.

[97] Yoon S, Lee C, Choi H, Kim H, Bae J. Impacting behavior of bulk metallic glass powder at an abnormally high strain rate during kinetic spraying. Materials Science and Engineering A 2007;448-451:911-915.

[98] Assadi H, Schmidt T, Richter H, Kliemann J, Binder K, Gärtner F, Klassen T, Kreye H. On parameter selection in cold spraying. Journal of Thermal Spray Technology 2011;20:1161-1176. 
[99] Bae G, Kang K, Na H, Kim J, Lee C. Effect of particle size on the microstructure and properties of kinetic sprayed nickel coatings. Surface and Coatings Technology 2010;204:3326-3335.

[100] Wu J, bFang H, Yoon S, Lee C., Kim H. Critical velocities for high speed particle deposition in kinetic spraying. Materials Transactions 2006;47:1723-1727.

[101] Wang FF, Li W, Yu M, Liao H. Prediction of critical velocity during cold spraying based on a coupled thermomechanical Eulerian model. Journal of Thermal Spray Technology 2014;23:60-67.

[102] Li W, Zhang C, Wang H, Guo XP, Liao H, Li C, Coddet C. Significant influences of metal reactivity and oxide films at particle surfaces on coating microstructure in cold spraying. Applied Surface Science 2007;253:3557-3562.

[103] Kang K, Yoon S, Ji Y, Lee C. Oxidation dependency of critical velocity for aluminum feedstock deposition in kinetic spraying process. Materials Science and Engineering A 2008;486:300-307.

[104] Ko KH, Choi JO, Lee H, Lee BJ. Influence of oxide chemistry of feedstock on cold sprayed Cu coatings. Powder Technology 2012;218:119-123.

[105] Kim K, Watanabe M, Kuroda S. Bonding mechanisms of thermally softened metallic powder particles and substrates impacted at high velocity. Surface and Coatings Technology 2010;204:2175-2180.

[106] Choi WB, Li L, Luzin V, Neiser R, Gnäupel-Herold T, Prask HJ, Sampath S, Gouldstone A. Integrated characterization of cold sprayed aluminum coatings. Acta Materialia 2007;55:857-866.

[107] Borchers C, Gärtner F, Stoltenhoff T, Assadi H, Kreye H. Microstructural and macroscopic properties of cold sprayed copper coatings. Journal of Applied Physics 2003;93:10064-10070. 
[108] Borchers C, Gärtner F, Stoltenhoff T, Kreye H. Formation of persistent dislocation loops by ultra-high strain-rate deformation during cold spraying. Acta Materialia 2005;53:2991-3000.

[109] Borchers C, Gärtner F, Stoltenhoff T, Kreye H. Microstructural bonding features of cold sprayed face centered cubic metals. Journal of Applied Physics 2004;96:4288-4292.

[110] Rokni M, Widener CA, Nardi A, Champagne VK. Nano crystalline high energy milled 5083 Al powder deposited using cold spray. Applied Surface Science 2014;305:797-804.

[111] Cho J, Jin Y, Park D, Kim H, Oh I, Lee K. Manufacture and properties of cold spray deposited large thickness $\mathrm{Cu}$ coating material for sputtering target. Metals and Materials International 2011;17:157-166.

[112] Kang K, Park H, Bae G, Lee C. Microstructure and texture of Al coating during kinetic spraying and heat treatment. Journal of Materials Science 2012;47:4053-4061.

[113] Zhang Y, Brodusch N, Descartes S, Chromik RR, Gauvin R. Microstructure refinement of cold-sprayed copper investigated by electron channeling contrast imaging. Microscopy and Microanalysis 2014;20:1499-1506.

[114] Goldbaum D, Chromik RR, Brodusch N, Gauvin R. Microstructure and mechanical properties of Ti cold-spray splats determined by electron channeling contrast imaging and nanoindentation mapping. Microscopy and Microanalysis 2015;21:570-581.

[115] Bae G, Kang K, Lee C. Nanoscale deformation twinning at ultrahigh strain rates during kinetic spraying of nickel. Materials Letters 2012;89:320-323.

[116] Li C, Li W, Wang Y. Formation of metastable phases in cold-sprayed soft metallic deposit. Surface and Coatings Technology 2005;198:469-473.

[117] Bae G, Kang K, Kim J, Lee C. Nanostructure formation and its effects on the mechanical properties of kinetic sprayed titanium coating. Materials Science and Engineering A 2010;527:6313-6319.

[118] Kang K, Won J, Bae G, Ha S, Lee C. Interfacial bonding and microstructural evolution of Al in kinetic spraying. Journal of Materials Science 2012;47:4649-4659. 
[119] Kim K, Watanabe M, Mitsuishi K, Iakoubovskii K, Kuroda S. Impact bonding and rebounding between kinetically sprayed titanium particle and steel substrate revealed by high-resolution electron microscopy. Journal of Physics D: Applied Physics 2009;42:65304.

[120] Eason PD, Kennett SC, Eden TJ, Krull I, Kowalski B, Jones JL. In situ observation of microstrain relief in cold-sprayed bulk copper during thermal annealing. Scripta Materialia 2012;67:791-794.

[121] Bae G, Jang J, Lee C. Correlation of particle impact conditions with bonding, nanocrystal formation and mechanical properties in kinetic sprayed nickel. Acta Materialia 2012;60:3524-3535.

[122] Birt AM, Champagne Jr. VK, Sisson Jr. RD, Apelian D. Microstructural analysis of cold-sprayed Ti-6Al-4V at the micro- and nano-scale. Journal of Thermal Spray Technology 2015;24:1277-1288.

[123] Zou Y, Goldbaum D, Szpunar JA, Yue S. Microstructure and nanohardness of coldsprayed coatings. Scripta Materialia 2010;62:395-398.

[124] Xiong Y, Kang K, Bae G, Yoon S, Lee C. Dynamic amorphization and recrystallization of metals in kinetic spray process. Applied Physics Letters 2008;92.

[125] Guetta S, Berger MH, Borit F, Guipont V, Jeandin M, Boustie M, Ichikawa Y, Sakaguchi K, Ogawa K. Influence of particle velocity on adhesion of cold-sprayed splats. Journal of Thermal Spray Technology 2009;18:331-342.

[126] Xiong Y, Xiong X, Yoon S, Bae G, Lee C. Dependence of bonding mechanisms of cold sprayed coatings on strain-rate-induced non-equilibrium phase transformation. Journal of Thermal Spray Technology 2011;20:860-865.

[127] Wang Q, Qiu D, Xiong Y, Birbilis N, Zhang M. High resolution microstructure characterization of the interface between cold sprayed $\mathrm{Al}$ coating and $\mathrm{Mg}$ alloy substrate. Applied Surface Science 2014;289:366-369. 
[128] Ko KH, Choi JO, Lee H. Pretreatment effect of $\mathrm{Cu}$ feedstock on cold-sprayed coatings. Journal of Materials Processing Technology 2014;214:1530-1535.

[129] Ko K, Choi JO, Lee H, Seo Y, Jung S, Yu S. Cold spray induced amorphization at the interface between Fe coatings and Al substrate. Materials Letters 2015;149:40-42.

[130] Zahiri SH, Fraser D, Jahedi M. Recrystallization of cold spray-fabricated CP titanium structures. Journal of Thermal Spray Technology 2009;18:16-22.

[131] Zou Y, Qin W, Irissou E, Legoux J, Yue S, Szpunar JA. Dynamic recrystallization in the particle/particle interfacial region of cold-sprayed nickel coating. Scripta Materialia 2009;61:899-902.

[132] Lee C, Kim J. Microstructure of kinetic spray coatings: A review. Journal of Thermal Spray Technology 2015;24:592-610.

[133] Luo X, Li C, Shang F, Yang G, Wang Y, Li C. High velocity impact induced microstructure evolution during deposition of cold spray coatings: A review. Surface and Coatings Technology 2014;254:11-20.

[134] Borchers C, Schmidt T, Gärtner F, Kreye H. High strain rate deformation microstructures of stainless steel 316L by cold spraying and explosive powder compaction. Applied Physics A: Materials Science and Processing 2008;90:517-526.

[135] Borchers C, Stoltenhoff T, Hahn M, Schulze M, Assadi H, Suryanarayana C, Gärtner F, Klassen T. Strain-induced phase transformation of MCrAlY. Advanced Engineering Materials 2015;17:723-731.

[136] Hall AC, Cook DJ, Neiser RA, Roemer TJ, Hirschfeld DA. The effect of a simple annealing heat treatment on the mechanical properties of cold-sprayed aluminum. Journal of Thermal Spray Technology 2006;15:233-238.

[137] Meng X, Zhang J, Han W, Zhao J, Liang Y. Influence of annealing treatment on the microstructure and mechanical performance of cold sprayed 304 stainless steel coating. Applied Surface Science 2011;258:700-704. 
[138] Huang R, Sone M, Ma W, Fukanuma H. The effects of heat treatment on the mechanical properties of cold-sprayed coatings. Surface and Coatings Technology $2015 ; 261: 278-288$.

[139] Gärtner F, Stoltenhoff T, Voyer J, Kreye H, Riekehr S, Koçak M. Mechanical properties of cold-sprayed and thermally sprayed copper coatings. Surface and Coatings Technology 2006;200:6770-6782.

[140] Klassen T, Gärtner F, Assadi H. Process science of cold spray, in: Kay CM, Karthikeyan J (Eds.). High Pressure Cold Spray: Principles and Applications: ASM International; 2016.

[141] Maev RG, Leshchynsky V, Strumban E, Dzhurinskiy D, Kocimski J, Maeva E. Structure and mechanical properties of thick copper coating made by cold spray. Journal of Thermal Spray Technology 2016;25:113-122.

[142] Huang R, Ma W, Fukanuma H. Development of ultra-strong adhesive strength coatings using cold spray. Surface and Coatings Technology 2014;258:832-841.

[143] Saleh M, Luzin V, Spencer K. Analysis of the residual stress and bonding mechanism in the cold spray technique using experimental and numerical methods. Surface and Coatings Technology 2014;252:15-28.

[144] Ghelichi R, Bagherifard S, MacDonald D, Fernandez-Pariente I, Jodoin B, Guagliano M. Experimental and numerical study of residual stress evolution in cold spray coating. Applied Surface Science 2014;288:26-33.

[145] Li W, Yang K, Zhang D, Zhou X. Residual stress analysis of cold-sprayed copper coatings by numerical simulation. Journal of Thermal Spray Technology 2016;25:131142.

[146] Spencer K, Luzin V, Matthews N, Zhang M. Residual stresses in cold spray Al coatings: The effect of alloying and of process parameters. Surface and Coatings Technology 2012;206:4249-4255. 
[147] Luzin V, Spencer K, Zhang M. Residual stress and thermo-mechanical properties of cold spray metal coatings. Acta Materialia 2011;59:1259-1270.

[148] Tsui YC, Clyne TW. An analytical model for predicting residual stresses in progressively deposited coatings. Thin Solid Films 1997;306:23-33.

[149] Suhonen T, Varis T, Dosta S, Torrell M, Guilemany JM. Residual stress development in cold sprayed Al, Cu and Ti coatings. Acta Materialia 2013;61:6329-6337.

[150] Arabgol Z, Assadi H, Schmidt T, Gärtner F, Klassen T. Analysis of thermal history and residual stress in cold-sprayed coatings. Journal of Thermal Spray Technology 2014;23:84-90.

[151] Wong W, Vo P, Irissou E, Ryabinin AN, Legoux J, Yue S. Effect of particle morphology and size distribution on cold-sprayed pure titanium coatings. Journal of Thermal Spray Technology 2013;22:1140-1153.

[152] Yin S, Wang X, Li W, Jie H. Effect of substrate hardness on the deformation behavior of subsequently incident particles in cold spraying. Applied Surface Science $2011 ; 257: 7560-7565$.

[153] Lupoi R, O’Neill W. Deposition of metallic coatings on polymer surfaces using cold spray. Surface and Coatings Technology 2010;205:2167-2173.

[154] Zhou X, Chen AF, Liu JC, Wu XK, Zhang JS. Preparation of metallic coatings on polymer matrix composites by cold spray. Surface and Coatings Technology 2011;206:132-136.

[155] Ganesan A, Affi J, Yamada M, Fukumoto M. Bonding behavior studies of cold sprayed copper coating on the PVC polymer substrate. Surface and Coatings Technology 2012;207:262-269.

[156] Gardon M, Latorre A, Torrell M, Dosta S, Fernández J, Guilemany JM. Cold gas spray titanium coatings onto a biocompatible polymer. Materials Letters 2013;106:97-99.

[157] King PC, Poole A, Horne S, Nys R, Gulizia S, Jahedi MZ. Embedment of copper particles into polymers by cold spray. Surface and Coatings Technology 2013;216:60-67. 
[158] Nakano H, Yamada M, Fukumoto M, Yamaguchi E. Microstructure of interfacial region between cold-sprayed copper coating and AlN substrate coated with sputtered titanium and copper. Journal of Thermal Spray Technology 2011;20:407-411.

[159] Legoux J, Irissou E, Moreau C. Effect of substrate temperature on the formation mechanism of cold-sprayed aluminum, zinc and tin coatings. Journal of Thermal Spray Technology 2007;16:619-626.

[160] Suo X, Yu M, Li W, Planche M, Liao H. Effect of substrate preheating on bonding strength of cold-sprayed Mg coatings. Journal of Thermal Spray Technology 2012;21:1091-1098.

[161] Xiong Y, Zhuang W, Zhang M. Effect of the thickness of cold sprayed aluminium alloy coating on the adhesive bond strength with an aluminium alloy substrate. Surface and Coatings Technology 2015;270:259-265.

[162] Yu M, Li W, Wang FF, Suo X, Liao H. Effect of particle and substrate preheating on particle deformation behavior in cold spraying. Surface and Coatings Technology 2013;220:174-178.

[163] Yin S, Suo X, Guo Z, Liao H, Wang X. Deposition features of cold sprayed copper particles on preheated substrate. Surface and Coatings Technology 2015;268:252-256.

[164] Yin S, Suo X, Xie Y, Li W, Lupoi R, Liao H. Effect of substrate temperature on interfacial bonding for cold spray of $\mathrm{Ni}$ onto $\mathrm{Cu}$. Journal of Materials Science 2015;50:7448-7457.

[165] Xie Y, Planche M, Raoelison R, Liao H, Suo X, Hervé P. Effect of substrate preheating on adhesive strength of SS 316L cold spray coatings. Journal of Thermal Spray Technology 2016;25:123-130.

[166] Watanabe Y, Yoshida C, Atsumi K, Yamada M, Fukumoto M. Influence of substrate temperature on adhesion strength of cold-sprayed coatings. Journal of Thermal Spray Technology 2014;24:86-91. 
[167] Ernst K, Braeutigam J, Gaertner F, Klassen T. Effect of substrate temperature on coldgas-sprayed coatings on ceramic substrates. Journal of Thermal Spray Technology 2013;22:422-432.

[168] Richer P, Jodoin B, Ajdelsztajn L, Lavernia EJ. Substrate roughness and thickness effects on cold spray nanocrystalline Al-Mg coatings. Journal of Thermal Spray Technology 2006;15:246-254.

[169] Marrocco T, McCartney DG, Shipway PH, Sturgeon A. Production of titanium deposits by cold-gas dynamic spray: Numerical modeling and experimental characterization. Journal of Thermal Spray Technology 2006;15:263-272.

[170] Sharma M, Eden TJ, Golesich B. Effect of surface preparation on the microstructure, adhesion, and tensile properties of cold-sprayed aluminum coatings on AA2024 substrates. Journal of Thermal Spray Technology 2014;24:410-422.

[171] Li W, Liao H, Wang H. Cold spraying of light alloys. Surface Engineering of Light Alloys: Aluminium, Magnesium and Titanium Alloys. Elsevier; 2010.

[172] Bala N, Singh H, Karthikeyan J, Prakash S. Cold spray coating process for corrosion protection: A review. Surface Engineering 2014;30:414-421.

[173] Champagne VK, Helfritch DJ. Mainstreaming cold spray - Push for applications. Surface Engineering 2014;30:396-403.

[174] Vilardell AM, Cinca N, Concustell A, Dosta S, Cano IG, Guilemany JM. Cold spray as an emerging technology for biocompatible and antibacterial coatings: State of art. Journal of Materials Science 2015;50:4441-4462.

[175] Gärtner F, Stoltenhoff T, Schmidt T, Kreye H. The cold spray process and its potential for industrial applications. Journal of Thermal Spray Technology 2006;15:223-232.

[176] Onizawa K, Schulze M, Gärtner F, Klassen T. Cold gas spraying of zinc and zinc alloy coatings for printing applications. Welding and Cutting 2012;11:128-133. 
[177] Ziemian C, Sharma M, Bouffard B, Nissley T, Eden TJ. Effect of substrate surface roughening and cold spray coating on the fatigue life of AA2024 specimens. Materials and Design 2014;54:212-221.

[178] Segall AE, Papyrin AN, Conway Jr. JC, Shapiro D. A cold-gas spray coating process for enhancing titanium. JOM 1998;50:52-54.

[179] Chavan NM, Ramakrishna M, Phani PS, Rao DS, Sundararajan G. The influence of process parameters and heat treatment on the properties of cold sprayed silver coatings. Surface and Coatings Technology 2011;205:4798-4807.

[180] Li W, Li C, Liao H, Coddet C. Effect of heat treatment on the microstructure and microhardness of cold-sprayed tin bronze coating. Applied Surface Science 2007;253:5967-5971.

[181] Guo X, Zhang G, Li W, Dembinski L, Gao Y, Liao H, Coddet C. Microstructure, microhardness and dry friction behavior of cold-sprayed tin bronze coatings. Applied Surface Science 2007;254:1482-1488.

[182] Krebs S, Gärtner F, Klassen T. Cold spraying of Cu-Al-bronze for cavitation protection in marine environments. Journal of Thermal Spray Technology 2014;24:126135.

[183] McCune RC, Donlon WT, Popoola OO, Cartwright EL. Characterization of copper layers produced by cold gas-dynamic spraying. Journal of Thermal Spray Technology 2000;9:73-82.

[184] Liu J, Zhou X, Zheng X, Cui H, Zhang J. Tribological behavior of cold-sprayed nanocrystalline and conventional copper coatings. Applied Surface Science 2012;258:7490-7496.

[185] Kim D, Park J, Lee J, Kim D, Tark SJ, Ahn S, Yun JH, Gwak J, Yoon KH, Chandra S, Yoon SS. Cold spray deposition of copper electrodes on silicon and glass substrates. Journal of Thermal Spray Technology 2013;22:1092-1102. 
[186] Goupil G, Jucken S, Poirier D, Legoux J, Irissou E, Davis B, Guay D, Roué L. Cold sprayed Cu-Ni-Fe anode for Al production. Corrosion Science 2015;90:259-265.

[187] Stier O. Fundamental cost analysis of cold spray. Journal of Thermal Spray Technology 2014;23:131-139.

[188] Champagne VK. Repair of magnesium components by cold spray techniques. The Cold Spray Materials Deposition Process: Fundamentals and Applications. Elsevier; 2007.

[189] Ajdelsztajn L, Jodoin B, Schoenung JM. Synthesis and mechanical properties of nanocrystalline Ni coatings produced by cold gas dynamic spraying. Surface and Coatings Technology 2006;201:1166-1172.

[190] Aghasibeig M, Monajatizadeh H, Bocher P, Dolatabadi A, Wuthrich R, Moreau C. Cold spray as a novel method for development of nickel electrode coatings for hydrogen production. International Journal of Hydrogen Energy 2015;41:227-238.

[191] Bala N, Singh H, Prakash S. High-temperature oxidation studies of cold-sprayed Ni20Cr and Ni-50Cr coatings on SAE 213-T22 boiler steel. Applied Surface Science 2009;255:6862-6869.

[192] Bala N, Singh H, Prakash S, Karthikeyan J. Investigations on the behavior of HVOF and cold sprayed $\mathrm{Ni}-20 \mathrm{Cr}$ coating on T22 boiler steel in actual boiler environment. Journal of Thermal Spray Technology 2012;21:144-158.

[193] Kumar M, Singh H, Singh N, Joshi R. Erosion-corrosion behavior of cold-spray nanostructured Ni-20Cr coatings in actual boiler environment. Wear 2015;332-333:10351043.

[194] Singh H, Sidhu TS, Karthikeyan J, Kalsi S. Evaluation of characteristics and behavior of cold sprayed $\mathrm{Ni}-20 \mathrm{Cr}$ coating at elevated temperature in waste incinerator plant. Surface and Coatings Technology 2015;261:375-384.

[195] Levasseur D, Yue S, Brochu M. Pressureless sintering of cold sprayed Inconel 718 deposit. Materials Science and Engineering A 2012;556:343-350. 
[196] Wong W, Irissou E, Vo P, Sone M, Bernier F, Legoux J, Fukanuma H, Yue S. Cold spray forming of Inconel 718. Journal of Thermal Spray Technology 2013;22:413-421.

[197] Tria S, Elkedim O, Li W, Liao H. Ball milled Ni-Ti powder deposited by cold spraying. Journal of Alloys and Compounds 2009;483:334-336.

[198] Tria S, Elkedim O, Hamzaoui R, Guo X, Bernard F, Millot N, Rapaud O. Deposition and characterization of cold sprayed nanocrystalline NiTi. Powder Technology 2011;210:181-188.

[199] Villa M, Dosta S, Guilemany JM. Optimization of 316L stainless steel coatings on light alloys using cold gas spray. Surface and Coatings Technology 2013;235:220-225.

[200] Al-Mangour B, Vo P, Mongrain R, Irissou E, Yue S. Effect of heat treatment on the microstructure and mechanical properties of stainless steel $316 \mathrm{~L}$ coatings produced by cold spray for biomedical applications. Journal of Thermal Spray Technology 2014;23:641-652.

[201] Coddet P, Verdy C, Coddet C, Debray F, Lecouturier F. Mechanical properties of thick 304L stainless steel deposits processed by He cold spray. Surface and Coatings Technology 2015;277:74-80.

[202] Cinca N, López E, Dosta S, Guilemany JM. Study of Stellite-6 deposition by cold gas spraying. Surface and Coatings Technology 2013;232:891-898.

[203] Cinca N, Guilemany JM. Structural and properties characterization of Stellite coatings obtained by cold gas spraying. Surface and Coatings Technology 2013;220:90-97.

[204] Lucchetta G, Giusti R, Vezzù S, Bariani P. Investigation and characterization of Stellite-based wear-resistant coatings applied to steel moulds by cold-spray. CIRP Annals - Manufacturing Technology 2015;64:535-538.

[205] Hussain T. Cold spraying of titanium: A review of bonding mechanisms, microstructure and properties. Key Engineering Materials 2013;533:53-90. 
[206] Vo P, Goldbaum D, Wong W, Irissou E, Legoux J, Chromik RR, Yue S. Cold-spray processing of titanium and titanium alloys, in: Titanium Powder Metallurgy: Elsevier; 2015. p. 405-423.

[207] Chavan NM, Kiran B, Jyothirmayi A, Phani PS, Sundararajan G. The corrosion behavior of cold sprayed zinc coatings on mild steel substrate. Journal of Thermal Spray Technology 2013;22:463-470.

[208] Choi H, Jo H, An K, Yoon S, Lee C. Tribological behavior of the kinetic sprayed Ni59Ti16Zr20Si2Sn3 bulk metallic glass. Journal of Alloys and Compounds 2007;434435:64-67.

[209] Yoon S, Kim J, Bae G, Kim B, Lee C. Formation of coating and tribological behavior of kinetic sprayed Fe-based bulk metallic glass. Journal of Alloys and Compounds 2011;509:347-353.

[210] Choi SJ, Lee HS, Jang JW, Yi S. Corrosion behavior in a $3.5 \mathrm{wt} \% \mathrm{NaCl}$ solution of amorphous coatings prepared through plasma-spray and cold-spray coating processes. Metals and Materials International 2014;20:1053-1057.

[211] List A, Gärtner F, Schmidt T, Klassen T. Impact conditions for cold spraying of hard metallic glasses. Journal of Thermal Spray Technology 2012;21:531-540.

[212] Noorakma A, Zuhailawati H, Aishvarya V, Dhindaw B. Hydroxyapatite-coated magnesium-based biodegradable alloy: Cold spray deposition and simulated body fluid studies. Journal of Materials Engineering and Performance 2013;22:2997-3004.

[213] Hasniyati M, Zuhailawati H, Sivakumar R, Dhindaw B. Optimization of multiple responses using overlaid contour plot and steepest methods analysis on hydroxyapatite coated magnesium via cold spray deposition. Surface and Coatings Technology 2015;280:250-255.

[214] Zhou X, Mohanty P. Electrochemical behavior of cold sprayed hydroxyapatite/titanium composite in Hanks' solution. Electrochimica Acta 2012;65:134140. 
[215] Sanpo N, Tan ML, Cheang P, Khor KA. Antibacterial property of cold-sprayed HAAg/PEEK coating. Journal of Thermal Spray Technology 2009;18:10-15.

[216] Yamada M, Isago H, Nakano H, Fukumoto M. Cold spraying of TiO 2 photocatalyst coating with nitrogen process gas. Journal of Thermal Spray Technology 2010;19:12181223.

[217] Lee J, Kim D, Park J, Cha Y, Yoon J, Jeon H, Min B, Swihart M, Jin S, Al-Deyab S, Yoon SS. Graphene-titania hybrid photoanodes by supersonic kinetic spraying for solar water splitting. Journal of the American Ceramic Society 2014;97:3660-3668.

[218] Gutzmann H. Kaltgasspritzen von Titandioxid - Bindungsverhalten und photokatalytische Eigenschaften: Thesis, Helmut-Schmidt-Universität, Hamburg; 2014.

[219] Gardon M, Guilemany JM. Milestones in functional titanium dioxide thermal spray coatings: A review. Journal of Thermal Spray Technology 2014;23:577-595.

[220] Herrmann-Geppert I, Bogdanoff P, Emmler T, Dittrich T, Radnik J, Klassen T, Gutzmann H, Schieda M. Cold gas spraying - A promising technique for photoelectrodes: The example TiO2. Catalysis Today 2016;260:140-147.

[221] Kang H, Kang SB. Tungsten/copper composite deposits produced by a cold spray. Scripta Materialia 2003;49:1169-1174.

[222] Voyer J, Stoltenhoff T, Schmidt T, Kreye H. Method and potential of the cold spray process, in: Heinrich P (Ed.). High-Velocity Oxy-Fuel Flame Spraying (HVOF) Colloquium; 2003. p. 39-47.

[223] Pialago E, Kwon O, Park CW. Cold spray deposition of mechanically alloyed ternary $\mathrm{Cu}-\mathrm{CNT}-\mathrm{SiC}$ composite powders. Ceramics International 2015;41:6764-6775.

[224] Maev RG, Leshchynsky V. Air gas dynamic spraying of powder mixtures: Theory and application. Journal of Thermal Spray Technology 2006;15:198-205.

[225] Kim H, Jung DJ, Lee C. The effect of Ni coating for diamond on the metal/diamond composite coatings by cold spray deposition, in: Proceedings of the International Thermal Spray Conference; 2009. 
[226] Pialago E, Park CW. Cold spray deposition characteristics of mechanically alloyed Cu-CNT composite powders. Applied Surface Science 2014;308:63-74.

[227] Lioma D, Sacks N, Botef I. Cold gas dynamic spraying of WC-Ni cemented carbide coatings. International Journal of Refractory Metals and Hard Materials 2015;49:365-373.

[228] Lima R, Karthikeyan J, Kay C, Lindemann J, Berndt CC. Microstructural characteristics of cold-sprayed nanostructured WC-Co coatings. Thin Solid Films 2002;416:129-135.

[229] Gao P, Li C, Yang G, Li Y, Li C. Influence of substrate hardness on deposition behavior of single porous WC-12Co particle in cold spraying. Surface and Coatings Technology 2008;203:384-390.

[230] Ji G, Chen X, Wang H, Bai X, Dong Z. Deformation behaviors of cold-sprayed WCCo particles. Journal of Thermal Spray Technology 2015;24:1100-1110.

[231] Couto M, Dosta S, Guilemany JM. Comparison of the mechanical and electrochemical properties of WC-17 and 12Co coatings onto Al7075-T6 obtained by high velocity oxyfuel and cold gas spraying. Surface and Coatings Technology 2015;268:180-189.

[232] Yu M, Chen H, Li W, Suo X, Liao H. Building-up process of cold-sprayed Al5056/In718 composite coating. Journal of Thermal Spray Technology 2014;24:579_ 586.

[233] Shockley J, Descartes S, Vo P, Irissou E, Chromik RR. The influence of Al2O3 particle morphology on the coating formation and dry sliding wear behavior of cold sprayed Al-Al2O3 composites. Surface and Coatings Technology 2015;270:324-333.

[234] Yu M, Suo X, Li W, Wang Y, Liao H. Microstructure, mechanical property and wear performance of cold sprayed A15056/SiCp composite coatings: Effect of reinforcement content. Applied Surface Science 2014;289:188-196.

[235] Ravi K, Ichikawa Y, Ogawa K, Deplancke T, Lame O, Cavaille J. Mechanistic study and characterization of cold-sprayed ultra-high molecular weight polyethylene-nanoceramic composite coating. Journal of Thermal Spray Technology 2016;25:160-169. 
[236] Woo D, Sneed B, Peerally F, Heer F, Brewer L, Hooper J, Osswald S. Synthesis of nanodiamond-reinforced aluminum metal composite powders and coatings using highenergy ball milling and cold spray. Carbon 2013;63:404-415.

[237] Woo D, Heer F, Brewer L, Hooper J, Osswald S. Synthesis of nanodiamondreinforced aluminum metal matrix composites using cold-spray deposition. Carbon 2015;86:15-25.

[238] Kang N, Coddet P, Liao H, Coddet C. The effect of heat treatment on microstructure and tensile properties of cold spray $\mathrm{Zr}$ base metal glass/Cu composite. Surface and Coatings Technology 2015;280:64-71.

[239] Guo X, Chen J, Yu H, Liao H, Coddet C. A study on the microstructure and tribological behavior of cold-sprayed metal matrix composites reinforced by particulate quasicrystal. Surface and Coatings Technology 2015;268:94-98.

[240] Khun N, Li R, Loke K, Khor KA. Effects of Al-Cr-Fe quasicrystal content on tribological properties of cold-sprayed titanium composite coatings. Tribology Transactions 2015;58:616-624.

[241] Dean S, Potter J, Yetter R, Eden TJ, Champagne V, Trexler M. Energetic intermetallic materials formed by cold spray. Intermetallics 2013;43:121-130.

[242] Bacciochini A, Bourdon-Lafleur S, Poupart C, Radulescu M, Jodoin B. Ni-Al nanoscale energetic materials: Phenomena involved during the manufacturing of bulk samples by cold spray. Journal of Thermal Spray Technology 2014;23:1142-1148.

[243] Jan V, Čupera J, Cizek J. On the search for producing intermetallics by diffusion reaction of cold spray bulk deposits. Surface and Coatings Technology 2015;268:216223.

[244] Bacciochini A, Radulescu MI, Yandouzi M, Maines G, Lee JJ, Jodoin B. Reactive structural materials consolidated by cold spray: Al-CuO thermite. Surface and Coatings Technology 2013;226:60-67. 
[245] Assadi H, Klassen T, Gärtner F, Nanbu T, Kawashita Y, Uehara Y. Modelling of impact and bonding of inhomogeneous particles in cold spraying, in: Proceedings of the International Thermal Spray Conference; 2014. 